\title{
The rational formula from the runhydrograph
}

\author{
Mohamed Parak and Geoffrey GS Pegram* \\ Civil Engineering Programme, University of KwaZulu-Natal, Durban, 4041, South Africa
}

\begin{abstract}
The rational formula is possibly the simplest flood estimation technique available using rainfall-runoff relationships. In spite of the many criticisms regarding its over-simplification of the processes of rainfall conversion into runoff, it remains possibly the most widely used method for estimating peak flood flows for urban drainage systems and small $\left(<100 \mathrm{~km}^{2}\right)$ rural catchments. However, as a result of the criticisms, the formula carries with it many cautions. One such caution regards the determination of the formula's runoff coefficient $c$, which is seen as the main difficulty in the design application of the formula. Mindful of this, it was decided to investigate the calibration of this coefficient, on past flood peak and flood volume pairs for a number of catchments in South Africa. To this end the "data set" of runhydrographs, which describe the characteristic peak and volume discharges of a catchment for a given recurrence interval, was used to calibrate the coefficients for selected catchments and to explore the assumptions underpinning this simple model. This article describes the methods employed in achieving this as well as a discussion of the results.
\end{abstract}

Keywords: design flood estimation, probabilistic rational formula, runhydrograph, calibration of runoff coefficients

\section{Introduction}

The rational formula is perhaps the best known and most widely used method for the determination of peak flood flows from rainfall events. It has survived numerous criticisms regarding its over-simplification of the complex hydrological processes of flood production but nonetheless is possibly the most favoured method used by practitioners for peak flood estimation. The rational formula owes its popularity to the fact that it is easy to understand and simple to use. The peak flood flow due to a rainfall event on a catchment, determined from the rational formula, is expressed (in SI units) as:

$$
Q_{R F}=c i A / 3.6
$$

where:

$$
Q_{R F} \text { is the flood peak in } \mathrm{m}^{3} / \mathrm{s}
$$

$c$ is the runoff coefficient, which is (in the traditional deterministic approach) defined as the proportion of precipitation that contributes to runoff

$i$ is the storm rainfall intensity in $\mathrm{mm} / \mathrm{h}$

$A$ is the catchment area in $\mathrm{km}^{2}$.

The criticisms concerning the rational formula in the above form are not unfounded and the use of this method carries valid cautions that are based on the following assumptions built into the formula (which are not always explicit in its presentation):

- The maximum rate of runoff from a catchment is achieved when the duration of rainfall is equal to the time of concentration $\left(T_{c}\right)$ of the catchment, which is defined as the time taken for the outflow from a catchment to reach near equilibrium due to a storm uniformly spread in space and time,

* To whom all correspondence should be addressed.

용 +2731 260-3057; fax: +2731 260-1411;

e-mail: pegram@ukzn.ac.za

Received 18 March 2005; accepted in revised form 30 January 2006.
- The spatial and temporal characteristics of rainfall are consequently ignored and the storm rainfall, as input into the formula, is assumed to be a rectangular pulse of duration $T$, deposited in lumped form on the catchment (i.e. there is no routing component implicit in the formula).

As a consequence, the rational formula was previously limited in its application to small catchments $\left(<15 \mathrm{~km}^{2}\right.$ in South Africa (HRU, 1972)) and was only to be used as a check method (it was not to be used in isolation). It was further noted that sound engineering experience and judgment was required for its use. However, work that has since been done, locally by Alexander (2002) and Pegram (2003), and abroad in Australia (Institute of Engineers Australia, 1987), has shown that these cautions were too timid and its use may well be extended beyond small catchments.

For the estimation of design floods, a probabilistic approach to the rational formula is needed, where the variables $c$ and $i$ (the runoff coefficient and rainfall intensity respectively) of the formula are associated with a probability of exceedance. A probabilistic approach is different to a deterministic approach (which is the form shown in Eq. (1)), as it does not involve the representation of a historic event. As opposed to the latter case, no unique combination of rainfall and catchment conditions (such as storm patterns, ground cover conditions, antecedent moisture conditions, etc) exist to reproduce the design flood. In a probabilistic approach, the rational formula is used to estimate, for a given probability of exceedance, the magnitude of the peak discharge from a site; this peak would be equivalent to a discharge estimated from a frequency analysis of flood records if a long and representative record were available at that site.

Pilgrim and Cordery (1993) stated that the design situation is exactly suited to the probabilistic approach of the rational formula and has little similarity with the deterministic rational formula, so that the criticisms associated with the deterministic approach are not necessarily valid for the probabilistic design case. Alexander (1990) stated that as the catchment size increases the value 
of $c$ becomes more probabilistic than deterministic in its derivation. The probabilistic approach to the rational formula has the same form as Eq. (1) but is defined more specifically as:

$$
Q_{(T)}=c_{(T)} i_{\left(T_{C}, T\right)} A / 3.6
$$

where:

$Q_{(T)}$ is the flood peak in $\mathrm{m}^{3} / \mathrm{s}$ of recurrence interval (RI) $T$-years

$c_{(T)}$ is the runoff coefficient for a $T$-year event

$i_{(T, T)}$ is the $T$-year storm rainfall intensity in $\mathrm{mm} / \mathrm{h}$ of duration equal to the time of concentration $\mathrm{T}_{c}(h)$ of the catchment

$A$ is the catchment area in $\mathrm{km}^{2}$.

In this approach, the value of $c_{(T)}$ purports to transform a $T$-year design storm $i_{(T c, T)}$, of duration $T_{c}$, into a $T$-year flood peak $Q_{(T)}$ for a catchment of area $A$. The variable $i_{(T c, T)}$ can be determined, for a particular site, from suitable intensity-duration-frequency (IDF) relationships of design storms. However, the estimation of the runoff coefficient $c_{(T)}$ remains the main source of uncertainty in the probabilistic application of the rational formula. It is the least precise variable of the rational formula, in spite of it being bounded in the interval $(0 ; 1)$, and suggests that a fixed ratio of peak runoff rate to rainfall rate exists for the site, which in reality is not the case (Chow et al., 1988: 497). It is this characteristic (the estimation of the design runoff coefficient) of the rational formula that forms the main focus of this article. To this end, this article investigates the calibration of the runoff coefficient, on past flood peak and flood volume pairs for a number of catchments in South Africa, to assist with its determination. The calibration of runoff coefficients on past floods is also the practice that was adopted in Australia (Institute of Engineers Australia, 1987). It was shown in Australia that the use of calibrated coefficients in a probabilistic approach to the rational formula could consistently provide flood estimates for catchments up to $250 \mathrm{~km}^{2}$. In this research, the "data set" of runhydrographs produced by Hiemstra and Francis (1979) was used to calibrate the coefficients in order to investigate this for the selected catchments.

In South African practice, the idea of calibrating the rational formula's runoff coefficient is not new. Alexander (2002) proposed a new standardised regional flood estimation technique called the standard design flood (SDF). This method is essentially a probabilistic approach to the rational formula, as advocated by Alexander (1990), utilising calibrated runoff coefficients. The SDF method is based on the calibration of the runoff coefficient against design floods determined from a frequency analysis, using the LOG-Pearson-III (LPIII) distribution, of recorded events from a number of catchments in South Africa. According to Alexander (2002), the SDF can be applied to all sizes of catchments in South Africa, ranging in size from $10 \mathrm{~km}^{2}$ to $40000 \mathrm{~km}^{2}$. Alexander has also suggested a standard design hydrograph for the SDF with a fixed triangular shape that has a rising limb equal to the time of concentration of the catchment $T_{c}$ and a falling limb equal to $2 T_{C}$, i.e. an effective time base-length of $3 T_{C}$. This idealised hydrograph is the same as that proposed by Rooseboom et al. (1981) where, in this instance, it is noted that the runoff volume is greater than the proportionate part of the storm rainfall that runs off during the time of concentration. In an independent test, the average ratio of Alexander's 50-year SDF flood peak to the 50-year LPIII flood peak was found to be approximately $210 \%$ (Görgens, 2002). Alexander's method was designed to be purposefully conservative and he states that the over-estimates fall within the range of uncertainties associated

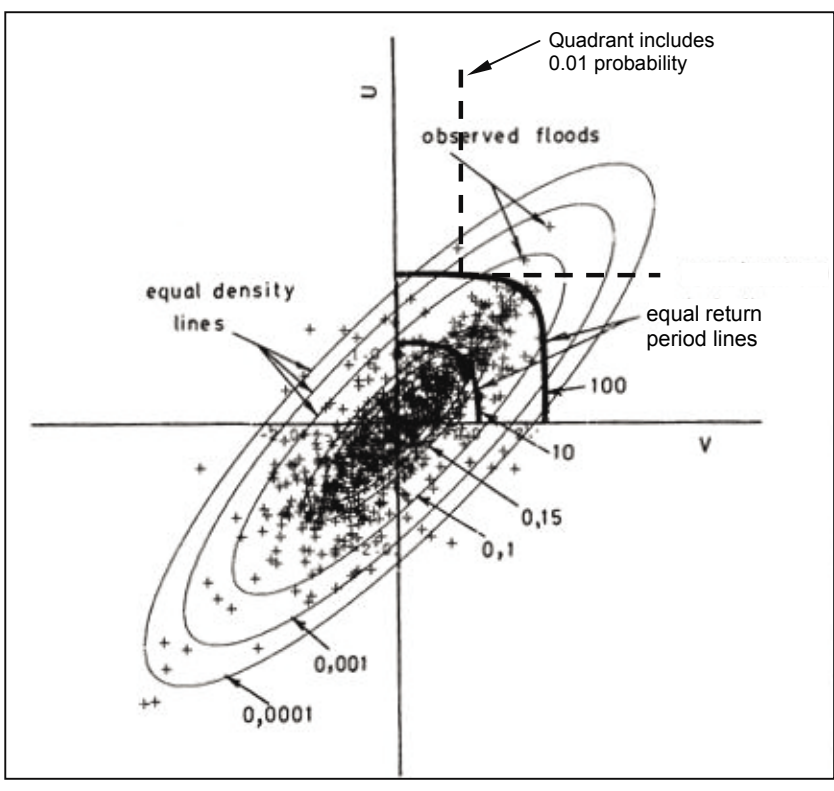

Figure 1

A standard bivariate normal probability density function, with a cross correlation coefficient of 0.85 , plotted with log-transformed observed flood peak-volume pairs in probability space (from Hiemstra and Francis, 1979: 14). The bold lines in the positive quadrant are the 10- and 100-year return period joint-exceedance contours. The dashed lines include a quadrant to the upper right which, on average, will include $1 \%$ of the observations.

within all design flood procedures. However, Görgens (2002) states that although the cost and implications associated with a conscious over-design in terms of a bridge/culvert is relatively minor, by contrast it is not acceptable for dam spillway design, where the cost of the spillway is a significant component of the total dam cost. An average over-estimate of $200 \%$ might render some projects infeasible. As such, Görgens recommends that the SDF should be seen as a conservative approach similar to that of the regional maximum flood (RMF) method.

Conscious of this, it was thought that where this investigation would add value would be in the calibration of the runoff coefficient on past flood peak and volume pairs, as offered by the runhydrograph method. Thus, it was hoped that this would yield coefficients that could, in a design situation, describe a complete design flood hydrograph (peak, volume and time base-length). The following sections describe and explain the theory behind the runhydrograph method, the methods employed in this investigation and the results achieved.

\section{The runhydrograph}

The runhydrograph method (Hiemstra and Francis, 1979) summarises, for a given catchment, the family of characteristic peak and volume discharges for a given recurrence interval. These hydrographs were based on the frequency analyses of all rare hydrographs (which were carefully screened for reliability) in a continuous stream flow record and, as such, are independent of rainfall input and catchment characteristics. This set of statistics was thus a valid data set against which to calibrate the runoff coefficient towards a probabilistic approach of the rational formula.

The runhydrograph method was developed by Hiemstra and Francis (1979) (in the sequel referred to as H\&F) and was 
based on earlier work by Hiemstra (1972; 1973; and 1974), Hiemstra et al. (1976) and Francis (1979). It is based on the joint probability analyses of same-event flood peak and flood volume pairs of recorded data from 43 catchments around South Africa (see Table A1 in the Appendix). H\&F discovered that the natural logarithms of the flood peak and its corresponding volume were approximately normally distributed and well correlated, with a cross-correlation coefficient with mean 0.78 and standard deviation 0.12 (a relatively narrow range) whose mode is 0.85 . Fig. 1 shows the natural logarithms of the recorded flood peak and volume pairs plotted together with the contours of equal probability density of a standardised bivariate normal probability density function (with a cross-correlation coefficient of 0.85 ). Also shown in Fig. 1 (in the positive quadrant) are 10- and 100-year return period exceedance probability contours (bold lines). The dashed lines intersecting on the 100-year exceedance contour define an area in the plane whose probability density integrates to 0.01 . Thus, on average, $1 \%$ of the observations will lie within this area, and within other areas defined similarly on the 100 -year contour.

The contours describe the joint probability of flood peak and flood volume exceedance and are able to produce "families" of hydrographs (peak-volume pairs) of equal probability of jointly being exceeded, but of varying shape. These families can range from the marginal peak (associated with any volume), to the "most likely" joint peak and volume pair through to the marginal volume, each with an equal probability of joint exceedance. However, it can be seen from Fig. 1 that the plotted peak-volume pairs cluster around the $45^{\circ}$ line in an elliptical shape. If the cross-correlation coefficient approaches unity, the minor axis of the ellipse reduces to zero. Thus, although more than one combination of a peak-volume pair exists that has the same probability of jointly being exceeded, the most likely (modal) pair will be found at the intersection of the $45^{\circ}$ line on the exceedance contour, the point where the probability density is highest.

Figure 2 shows the application of the runhydrograph method for design flood peak and volume estimation for a cross-correlation coefficient of 0.85 . The listed numbers on the top right of Fig. 3 are the standardised ordinates of the peak-volume exceedance contours for the selected recurrence intervals. They describe the joint exceedance of the most likely peak-volume pair (corresponding to line \#1) through to the exceedance of the marginal peak (corresponding to the vertical axis to the left of line \#6). It is unlikely that a peak-volume pair will occur on lines
4, 5 and 6 for this relatively high correlation, and thus for the purposes of this investigation the modal peak-volume pair was chosen in order to limit the number of variables.

In passing, it is interesting to note that this idea of describing hydrographs with a joint probability of exceedance of peak and volume, has surfaced again more recently to be exploited in the evaluation of dam safety (De Michele et al., 2005).

\section{Method and results}

The methods employed in this investigation were typical of those used in the derivation of a probabilistic rational formula utilising calibrated coefficients, of which an explanation follows which is adapted from Pilgrim and Cordery (1993) (quotes appearing in italics): 
- Where a set of long and reliable record of flood data from a particular catchment exists, a frequency analysis should be carried out on the observed data to determine design values of flood peaks for a range of recurrence intervals. In this study, flood peak and volume pairs $\left(Q_{T}\right.$ in $\mathrm{m}^{3} / \mathrm{s}$ and $V_{T}$ in $\mathrm{m}^{3}$ respectively) for the 'most likely' runhydrograph was computed for each of the selected catchments for RIs of 10-, 20-, 50-, 100- and 200-years. These appear in Tables A2 to A6 in Appendix A. As a result of this, values of $B$, the time baselength of the triangular approximated hydrographs, were also computed.

- A design formula for the calculation of time of concentration $T_{c}$ must be selected and used consistently throughout the derivation and use of this method. In this study the Kirpich (1940) formula was used, following the lead of Petras and Du Plessis (1987):

$$
T_{C}=0.0633\left[L^{2} / S\right]^{0.385}
$$

where:

$T$ is the catchment's time of concentration (in hours)

$L$ is the length (in $\mathrm{km}$ ) of the longest water course

$S$ is the slope of the longest water course.

- Design rainfall intensities, $i_{(T c, T)}$, for the corresponding time of concentration of the catchment and recurrence interval should be determined from a suitable Intensity-DurationFrequency (IDF) database. These were determined from Smithers and Schulze's (2002) design rainfall data-base for South Africa. These data appear in the same tables in the Appendix. (A computer program with a graphical user interface has been developed to obtain design rainfall depths for any location in South Africa from this database. The software may be downloaded from the following website: http://www.beeh.unp.ac.za/hydrorisk and follow the "Design Rainfall" option).

- From these data, values of $c_{(T)}$ can be back calculated by the following equation (where the variables are as defined for Eq. (2)):

$$
C_{(T)}=\frac{3.6 \cdot Q_{T}}{i_{T_{c}, T} \cdot A}
$$

This data also appears in the same tables in the Appendix.

- These calibrated values of $c_{(T)}$ can then be regressed on any physical characteristic of the catchment. In order to validate th e calibrated coefficients at untested sites, regional parameters with which to relate $c_{(T)}$ with RI were sought. However, it was noted by Pilgrim and Cordery (1993) that the probabilistic runoff coefficients determined for Australia did not show much sensitivity to physical characteristics of a catchment.

It is important to note that the values of $c_{(T)}$ obtained in this manner are conditioned on the use of a consistent formula for the calculation of $T$ and a consistent database for the derivation of the IDF rainfall relationships. A detailed explanation of each of the steps listed above and the results of each exercise are given in the following subsections.

\section{The streamflow database}

The 43 catchments used by H\&F in their study were based on the Department of Water Affairs and Forestry's drainage region delineations. These and their derived statistics are listed in Table A1 in the Appendix. As a point of departure, runhydrograph data from $\mathrm{H} \& \mathrm{~F}$ were combined with catchment parameters from Petras and Du Plessis (1987), namely area $(A)$ and time of concentration ( $T_{c}$ - based on Kirpich's formula). The number of catchments from the $\mathrm{H} \& \mathrm{~F}$ database, for which $T_{c}$ values were available from the Petras and Du Plessis catalogue, reduced the number of available catchments for calibration to 29. These are listed in Table A2 in the Appendix and formed the core data set on which the rational formula calculations were performed.

\section{The rainfall database}

For each of the 29 catchments, a number of locations (depending on the size of the catchment) along the main watercourse within the catchment were chosen for which design rainfall estimates were obtained from Smithers and Schulze (2002). The output from this rainfall database provides point rainfall depths (in $\mathrm{mm}$ ) for durations ranging from 5 minutes to 7 days and for return periods ranging from 2 to 200 years at a spatial resolution of 1 arc minute in South Africa. The mean depth for each catchment was computed and thereafter the intensity, duration and frequency (IDF) relationships were computed by fitting a simple power-law function of storm duration to the mean rainfall depths. For the selected recurrence intervals, these took the form of: $P$ (rainfall depth in $\mathrm{mm})=a \mathrm{~d}^{b}$ and $i$ (rainfall intensity in $\mathrm{mm} / \mathrm{hr})=a \mathrm{~d}^{-c}$, where $d$ is the storm duration in hours and $a$, $b$ and $c$ (which equals $b-1$ ) are the fitted power-law parameters. The mean intensity, corresponding to the time of concentration $T_{c}$, was calculated from the IDF relationships for the 10-, 20-, 50-, 100- and 200-year recurrence intervals for each catchment. The parameters fitted to the rainfall duration, for the selected recurrence intervals, are listed in the Appendix (Tables A2 to A8). It was found that rainfall depth scaled, on average, to the power of 0.238 of rainfall duration and thus rainfall intensity to the power of -0.762 of rainfall duration with a standard deviation of 0.0419 .

Area reduction factors (ARFs) were not used in this study to scale the point rainfall depths into average depths over the catchment. Instead simple averages of a few representative points along the longest watercourse within the catchment, determined from the Smithers and Schulze (2002) database, were used to account for the variation in precipitation with position and altitude for large catchments. ARFs were deemed not necessary based on the findings of Pegram (2003), of which a summary is presented here. He investigated the scaling properties of rainfall in South Africa and found that they could be expressed as a function of three factors: the median one-day rainfall (which is a function of location), a function of return period (the reduced variate of the general extreme value (GEV) distribution) and a function of duration. He used this finding to modify the intensity expression of the rational formula. The storm duration used by Pegram was the catchment's time of concentration $T_{c}$, as in this study, from the Kirpich (1940) formula. When this duration $T_{c}$ was plotted against catchment area, it was found that the points clustered about a curve to which a power-law relationship could be fitted. This was superimposed on the area reduction factor (ARF) diagram, published in the Flood Studies Report (FSR, 1975). He found that the Area $\sim T_{c}$ curve yielded an almost constant ARF value of $87 \%$ across the FSR curve. The implication of this is that, as long as the precipitation intensity used in the rational formula corresponds to the time of concentration of the catchment, the point rainfall is automatically scaled by a constant ARF. It is likely 
that the FSR's ARF curves over-estimate the relationship in South Africa, but the degree is likely to be a matter of climate (Pegram and Parak, 2004), so it is also likely that the scaling behaviour will be maintained. However, the reduction factor would automatically be absorbed into the fitted $c_{(T)}$-values. The first thing to note then is that because $c$ is explicitly a function of $T$, it is therefore implicitly independent of the ARF.

\section{Calibration of the runoff coefficients $\left(c_{(T)}\right)$}

The next thing to explore was the dependency of $c$ on the flood regime of catchments of various sizes and locations. The first task was to relate $c$ to the peaks of each catchment for varying recurrence interval, T. $c$-values were fitted to the flood peak of the calculated modal runhydrograph at each site, using the parameters for that site as estimated by $H \& F$.

The summary of results from the calibration of the runoff coefficients is shown below in Table 1. They are the 10-, 20-, 50-, 100 - and 200-year runoff coefficients for each of the 29 catchments that formed the core data set. These data and results are drawn from the Appendix (Tables A2 to A6).

Coefficients from 6 of the 29 catchments (marked with an asterisk in Table 1) produced results that did not increase in magnitude with recurrence interval. As mentioned in Alexander (1990), an increase in $c$ with recurrence interval is necessary to accommodate the known effects which also increase with rainfall intensity but are not accounted for in the formula's calculation process. The main effect, requiring this increase of $c$ with recurrence interval, is that the catchment is likely to be more saturated at the start of a storm with a longer recurrence interval (Rooseboom et al., 1981). This initial saturation caused by preevent rainfall is the main reason why one can expect to obtain a higher percentage runoff with an increase in the recurrence interval of an event. Alexander (2002) states that in many of the destructive events observed, severe rainfall events were often preceded by above-normal seasonal rainfall.

The calibrated values of $c$ (values of $c_{(T)}$ for all 29 catchments) were coaxially plotted with $c$-values from Chow et al. (1988: 498) against recurrence interval. This relationship is shown in Fig. 3, where the coefficients from Chow et al. (1988) correspond to the "flat" slopes type (i.e. for ground slopes between 0 and $2 \%$, since all the test catchments in this calibration exercise had slopes of less than 2\%) and are for the three "undeveloped" (rural) coverage types (i.e. cultivated land, pasture/range and forest/woodland). These values are shown in Table 2 and were determined for small rural catchments (i.e. less than $100 \mathrm{~km}^{2}$ ) of Austin, Texas (USA).

\section{TABLE 1}

The results of the calibration of the $c$-coefficient of the rational formula on flood peak and flood volume pairs from Hiemstra and Francis (1979)

\begin{tabular}{|c|c|c|c|c|c|c|c|c|c|c|c|}
\hline \multirow[t]{2}{*}{ Num. } & \multirow[t]{2}{*}{ Station } & \multirow[t]{2}{*}{ River } & \multirow{2}{*}{$\begin{array}{l}\text { Latitude } \\
\text { (degrees } \\
\text { decimal) }\end{array}$} & \multirow{2}{*}{$\begin{array}{l}\text { Longi- } \\
\text { tude } \\
\text { (degrees } \\
\text { decimal) }\end{array}$} & \multirow{2}{*}{$\begin{array}{c}\text { Catch- } \\
\text { ment } \\
\text { area } \\
\left(\mathrm{km}^{2}\right)\end{array}$} & \multirow{2}{*}{$\begin{array}{c}\text { Time of } \\
\text { concen- } \\
\text { tration } \\
T_{c} \\
\text { (hours) }\end{array}$} & \multicolumn{5}{|c|}{ Calibrated $c$-coefficients } \\
\hline & & & & & & & $\begin{array}{c}10- \\
\text { year }\end{array}$ & $\begin{array}{c}20- \\
\text { year }\end{array}$ & $\begin{array}{c}50- \\
\text { year }\end{array}$ & $\begin{array}{l}\text { 100- } \\
\text { year }\end{array}$ & $\begin{array}{l}200- \\
\text { year }\end{array}$ \\
\hline 1 & A2M03 & Hex & 25.77 & 27.28 & 494 & 6.4 & 0.301 & 0.303 & 0.304 & 0.305 & 0.306 \\
\hline 2 & A2M12 & Krokodil & 25.82 & 27.92 & 2586 & 18 & 0.089 & 0.093 & 0.095 & 0.097 & 0.098 \\
\hline 3 & A3M01 & Klein Marico & 25.53 & 26.10 & 1002 & 8.7 & 0.084 & 0.092 & 0.104 & 0.113 & 0.123 \\
\hline 4 & B2M01 & Bronkhorstspruit & 25.80 & 28.77 & 1585 & 18.1 & 0.210 & 0.228 & 0.244 & 0.254 & 0.262 \\
\hline 5 & B4M03 & Steelpoort & 25.02 & 29.53 & 2271 & 19.6 & 0.091 & 0.102 & 0.112 & 0.125 & 0.135 \\
\hline $6^{*}$ & B7M04 & Klaserie & 24.55 & 31.03 & 130 & 3.7 & 0.234 & 0.233 & 0.214 & 0.227 & 0.224 \\
\hline 7 & C1M01 & Vaal & 26.95 & 29.27 & 8254 & 74 & 0.396 & 0.419 & 0.444 & 0.460 & 0.476 \\
\hline 8 & C4M01 & Groot Vet & 28.48 & 26.67 & 5504 & 34 & 0.368 & 0.386 & 0.409 & 0.425 & 0.442 \\
\hline $9 *$ & C4M02 & Vet & 27.85 & 25.90 & 17550 & 111 & 0.179 & 0.175 & 0.170 & 0.167 & 0.164 \\
\hline 10 & C5M03 & Modder & 29.17 & 26.58 & 1650 & 18.3 & 0.419 & 0.440 & 0.458 & 0.469 & 0.479 \\
\hline 11 & C5M04 & Modder & 28.85 & 26.18 & 5012 & 38 & 0.528 & 0.592 & 0.660 & 0.706 & 0.749 \\
\hline 12 & C5M12 & Riet & 29.65 & 25.98 & 2383 & 23 & 0.218 & 0.235 & 0.252 & 0.264 & 0.274 \\
\hline 13 & C5M15 & Modder & 28.80 & 26.10 & 6545 & 43 & 0.280 & 0.302 & 0.325 & 0.341 & 0.355 \\
\hline 14 & C7M01 & Renoster & 27.27 & 27.18 & 5255 & 57 & 0.236 & 0.300 & 0.379 & 0.438 & 0.498 \\
\hline 15 & D1M05 & Oranje & 30.03 & 28.50 & 10891 & 60 & 0.261 & 0.266 & 0.270 & 0.272 & 0.274 \\
\hline $16^{*}$ & D5M01 & Renoster & 31.65 & 20.62 & 2129 & 27 & 0.263 & 0.264 & 0.264 & 0.264 & 0.264 \\
\hline $17 *$ & D5M04 & Sak & 31.65 & 21.77 & 5799 & 28 & 0.130 & 0.128 & 0.125 & 0.123 & 0.121 \\
\hline 18 & E2M02 & Doring & 32.50 & 19.53 & 5778 & 30 & 0.389 & 0.420 & 0.459 & 0.487 & 0.516 \\
\hline 19 & H1M06 & Bree & 33.42 & 19.27 & 754 & 7.6 & 0.454 & 0.457 & 0.461 & 0.464 & 0.468 \\
\hline $20^{*}$ & H1M07 & Wit & 33.57 & 19.15 & 83 & 2.4 & 0.814 & 0.800 & 0.790 & 0.787 & 0.786 \\
\hline 21 & H7M04 & Huis & 33.92 & 20.72 & 26 & 2.3 & 0.278 & 0.307 & 0.336 & 0.353 & 0.368 \\
\hline 22 & J2M03 & Gamka & 33.53 & 21.65 & 17941 & 42 & 0.076 & 0.082 & 0.090 & 0.095 & 0.099 \\
\hline 23 & J3M04 & Olifants & 33.48 & 23.03 & 4330 & 23 & 0.163 & 0.180 & 0.194 & 0.200 & 0.205 \\
\hline 24 & Q1M01 & Groot Vis & 31.90 & 25.48 & 9150 & 18 & 0.089 & 0.097 & 0.108 & 0.116 & 0.124 \\
\hline 25 & Q9M10 & Groot Vis & 33.22 & 26.87 & 29376 & 108 & 0.176 & 0.227 & 0.282 & 0.318 & 0.349 \\
\hline 26 & Q9M12 & Groot Vis & 33.10 & 26.45 & 23041 & 85 & 0.113 & 0.133 & 0.158 & 0.178 & 0.198 \\
\hline $27 *$ & T3M02 & Kinira & 30.48 & 28.62 & 2100 & 26 & 0.186 & 0.172 & 0.156 & 0.145 & 0.135 \\
\hline 28 & W4A03 & Pongola & 27.42 & 31.52 & 5843 & 31 & 0.267 & 0.278 & 0.284 & 0.285 & 0.284 \\
\hline 29 & W5M05 & Hlelo & 26.83 & 30.73 & 751 & 17.8 & 0.177 & 0.193 & 0.212 & 0.225 & 0.237 \\
\hline
\end{tabular}




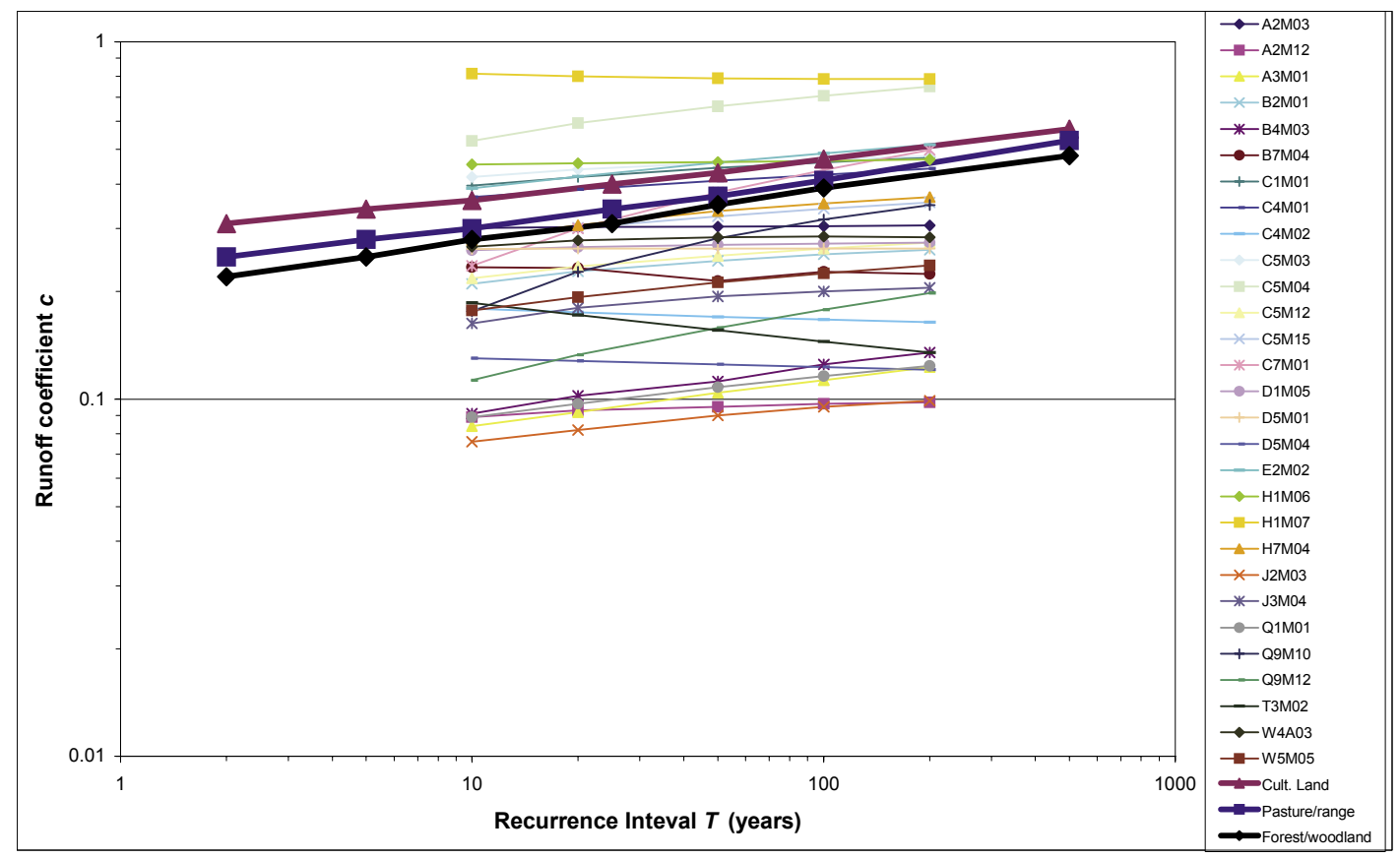

Figure 3

A comparison of the runoff coefficients $c$ from Chow et al. (1988: 498) with those calibrated in this study $\mathrm{C}_{(T)}$. The c-values plotted from Chow et al. are shown in thick bold lines and extend from the 2- to 500-year recurrence intervals.

It is evident from Fig. 3 that the $c_{(T)}$-values obtained from this exercise are spread around those of Chow et al. (1988) but are generally lower in magnitude. The $c_{(T)}$-values obtained from this exercise range from 0.084 to 0.786 , while the values from Chow et al. are between 0.28 and 0.57 (for the recurrence interval range of 10 - to 200 -years). However, the scatter associated with the latter data set is not known and hence not shown, so it is conjectured that they are curves fitted to the high side of the original data.

\section{Hydrograph time base-length $B$}

The use of flood peak and volume pairs for calibration in this investigation (from the runhydrograph method of H\&F (1979)) was thought to have the added advantage in that complete design flood hydrographs could be calculated from these calibrated coefficients. From the flood database computed for the calibration exercise, hydrograph time base-lengths $B$ for each RI were determined for each catchment. Out of interest, they were then expressed as ratios to the catchment's time of concentration $T_{c}$ for the respective recurrence intervals (which, in terms of the rational formula, is effectively a ratio to the hydrograph's time to peak). The average ratio of $B / T_{c}$, for each recurrence interval, was then determined and the results are presented in Table 3 together with their standard deviations. These results exclude three catchments whose area is $130 \mathrm{~km}^{2}$ or less as they gave $B / T$ ratios in excess of 7 . It is noted here that there is an increase of base-length with recurrence interval, which means that the volumes of the floods relative to the peaks, as modelled by the runhydrograph, also increase with $T$. The figures in the third row of Table 3 show the proportion of floods whose base-
TABLE 2

Runoff coefficients for use in the rational method for undeveloped (rural) regions in Austin, Texas in the USA (from Chow et al., 1988: 498) Runoff coefficients $c$

\begin{tabular}{|c|c|c|c|c|c|c|c|c|}
\hline $\begin{array}{l}\text { Character } \\
\text { of surface }\end{array}$ & $\begin{array}{c}2- \\
\text { year }\end{array}$ & $\begin{array}{c}5- \\
\text { year }\end{array}$ & $\begin{array}{c}10- \\
\text { year }\end{array}$ & $\begin{array}{c}25- \\
\text { year }\end{array}$ & $\begin{array}{c}50- \\
\text { year }\end{array}$ & $\begin{array}{l}100- \\
\text { year }\end{array}$ & $\begin{array}{c}200- \\
\text { year } \\
\text { (inter- } \\
\text { polated) }\end{array}$ & $\begin{array}{l}500- \\
\text { year }\end{array}$ \\
\hline \multicolumn{9}{|l|}{ Undeveloped } \\
\hline \multicolumn{9}{|l|}{ Cultivated land } \\
\hline Flat, $0-2 \%$ & 0.31 & 0.34 & 0.36 & 0.40 & 0.43 & 0.47 & 0.51 & 0.57 \\
\hline Average, $2-7 \%$ & 0.35 & 0.38 & 0.41 & 0.44 & 0.48 & 0.51 & 0.55 & 0.60 \\
\hline Steep, $>7 \%$ & 0.39 & 0.42 & 0.44 & 0.48 & 0.51 & 0.54 & 0.57 & 0.61 \\
\hline \multicolumn{9}{|l|}{ Pasture/range } \\
\hline Flat, $0-2 \%$ & 0.25 & 0.28 & 0.3 & 0.34 & 0.37 & 0.41 & 0.46 & 0.53 \\
\hline Average, $2-7 \%$ & 0.33 & 0.36 & 0.38 & 0.42 & 0.45 & 0.49 & 0.52 & 0.58 \\
\hline Steep, $>7 \%$ & 0.37 & 0.4 & 0.42 & 0.46 & 0.49 & 0.53 & 0.56 & 0.60 \\
\hline \multicolumn{9}{|l|}{ Forest/woodlands } \\
\hline Flat, $0-2 \%$ & 0.22 & 0.25 & 0.28 & 0.31 & 0.35 & 0.39 & 0.42 & 0.48 \\
\hline Average, $2-7 \%$ & 0.31 & 0.34 & 0.36 & 0.4 & 0.43 & 0.47 & 0.50 & 0.56 \\
\hline Steep, $>7 \%$ & 0.35 & 0.39 & 0.41 & 0.45 & 0.48 & 0.52 & 0.54 & 0.58 \\
\hline
\end{tabular}
approximately one third.

\section{Validation of the runoff coefficients $\left(c_{(T)}\right)$}

The purpose of validation is to test whether the model operates in the manner for which it was designed in "ways that were not explicitly built into the model" (Basson et al., 1994). Validation tests are necessary to convey confidence that the model works as expected. In order to validate the $c_{(T)}$-values achieved in calibration, it was necessary to find some physical regional descriptor(s) on which to regress the coefficients. This was required so that the calibrated coefficients may be extended to un-gauged catchments.

Several regional descriptors were tested in combination with the $c_{(T)}$-values to examine if a relationship existed on which to 


\begin{tabular}{|c|c|c|c|c|c|}
\hline \multicolumn{6}{|c|}{$\begin{array}{l}\text { TABLE } 3 \\
\text { The mean and standard deviations of the ratio of } \\
\text { the hydrograph time base-length } B \text { to the catch- } \\
\text { ments' time of concentration } T_{c} \text { as a function of } \\
\text { recurrence interval } T \text {. The proportion of } B / T_{c} \text { values } \\
\text { above } 3 \text { in each group are given in the third row. }\end{array}$} \\
\hline $\begin{array}{l}\text { Recurrence inter- } \\
\text { val } T \text { (years) }\end{array}$ & 10 & 20 & 50 & 100 & 200 \\
\hline Mean of $B / T$ ratios & 1.92 & 2.06 & 2.25 & 2.40 & 2.56 \\
\hline Standard deviation & 0.981 & 1.09 & 1.29 & 1.48 & 1.71 \\
\hline Proportion $>3$ & 0.14 & 0.19 & 0.28 & 0.34 & 0.40 \\
\hline
\end{tabular}

regress the coefficients. Descriptors such as catchment slope, mean annual precipitation (MAP), percentages of land coverage and Kovaćs' regional $K$-values (Kovaćs, 1988) were tested. From these analyses, no meaningful relationships between any of the descriptors tested and the $c_{(T)}$-coefficients were found. There were also no relationships found between parameters (multiplier and exponent) of a power-law function fitted to the $c_{(T)}$-values as a function of recurrence interval and regional descriptors. This result is in line with the comments of Pilgrim and Cordery (1993) for conditions in Australia, where the calibrated runoff coefficients did not show much sensitivity to catchment characteristics and indicate that the $c$-values are essentially functions of $T$ and $T_{c}$ as conjectured. Because there was no dependency observed between $c$-values and catchment properties, we were left with a problem: what values to use for validation?

It was decided to use the curves from Chow et al. (1988: 498), shown in Fig. 3, where it can be seen that the calibrated coefficients are generally lower than those of Chow et al. and the latter coefficients can be viewed as an approximate upper bounding set of curves. This choice, although conservative, was based on the premise that a practitioner will make a choice of the value of $c$ based on catchment slope and land usage, knowing that it is bounded in the interval (0.1) and usually in the range 0.3 to 0.6 .

Twenty-one catchments, which were not used in the calibration exercise and for which flood records were available, were selected for validation. These catchments ranged in size from $126 \mathrm{~km}^{2}$ to $24044 \mathrm{~km}^{2}$. The flood records were modelled using a general extreme value (GEV) distribution in a previous study (Pegram and Parak, 2004) which was shown to be the most appropriate distribution generally speaking for flood peaks in the region. For these catchments, times of concentration $\left(T_{c}\right)$ values were obtained from Petras and Du Plessis (1987) and representative design rainfall intensities from Smithers and Schulze (2002) in the same manner as for the calibration set. These data are summarised in Table A7 (Parts 1, 2 and 3) in the Appendix.

In order to obtain appropriate $c$-values from Chow et al. (1988: 498) for each catchment, it was necessary to relate the land coverage type and slope of each catchment with theirs (see Table 2 above). These catchment characteristics are given in Petras and Du Plessis (1987) where the percentages of land coverage for each catchment are catalogued as forest, dense bush wood, thin bush wood, cultivated land, grass and bare. At this stage it then became necessary to relate each catchment's coverage type (Petras and Du Plessis, 1987) to the generalised coverage types of Chow et al. (1988: 498). In order to easily accomplish this, several assumptions were made. They were:

- That the greatest percentage of land coverage (the modal type) was representative of the entire catchment

- That the following coverage types (from the descriptions of
Petras and Du Plessis (1987) and Chow et al. (1988) respectively) were equivalent (shown in Table 4 below).

\begin{tabular}{|c|c|}
\hline \multicolumn{2}{|c|}{$\begin{array}{c}\text { TABLE } 4 \\
\text { Equivalent land coverage types from the descrip- } \\
\text { tions of Petras and Du Plessis (1987) and Chow et } \\
\text { al. (1988: } 498)\end{array}$} \\
\hline \multicolumn{2}{|c|}{ Equivalent land coverage types } \\
\hline $\begin{array}{l}\text { Actual catchment land coverage } \\
\text { (as described in Petras and Du } \\
\text { Plessis (1987)) }\end{array}$ & $\begin{array}{l}\text { c-coefficient land cover- } \\
\text { ages (as listed in Chow et al. } \\
(1988: 498))\end{array}$ \\
\hline Forest & Forest/woodland \\
\hline Dense bush wood & Forest/woodland \\
\hline Thin bush wood & Forest/woodland \\
\hline Cultivated land & Cultivated land \\
\hline Grass & Pasture/range \\
\hline Bare & Cultivated land \\
\hline
\end{tabular}

From the above procedure, design flood peaks were obtained using the rational formula method $\left(Q_{R F}\right)$, i.e. a function of catchment area, design rainfall (of duration equal to the catchment time of concentration and the desired recurrence interval) and the runoff coefficients from Table 2. These design flood peaks were compared with the statistically modelled flood peaks $\left(Q_{G E V}\right)$, from the same catchments, for the corresponding recurrence intervals. The results of this exercise, for the 10-, 50- and 200-year recurrence intervals are shown in Figs. 4, 5 and 6 respectively and are summarised for all recurrence intervals in Table 5.

Although there is a fairly large scatter around the trend-line in log-space in Figs. 4, 5 and 6, some conclusions can be drawn from this validation exercise.

\section{TABLE 5}

A summary of the power-law curves, of the form $Q_{R F}=a Q_{G E V}^{b}$, fitted to the graphs of $Q_{R F}$ vs. $Q_{G E V}$ (where $Q_{R F}$ are the flood peaks obtained from the rational formula and $Q_{G E V}$ are the statistically modelled flood peaks). The average ratio of $Q_{R F} / Q_{G E V}$ for each recurrence interval is also given.

\begin{tabular}{|l|l|l|l|l|l|}
\hline $\begin{array}{l}\text { Recurrence in- } \\
\text { terval } \boldsymbol{T} \text { (years) }\end{array}$ & $\mathbf{1 0}$ & $\mathbf{2 0}$ & $\mathbf{5 0}$ & $\mathbf{1 0 0}$ & $\mathbf{2 0 0}$ \\
\hline Factor: $\boldsymbol{a}$ & 5.44 & 5.10 & 5.17 & 5.75 & 7.03 \\
\hline Exponent: $\boldsymbol{b}$ & 0.795 & 0.798 & 0.785 & 0.766 & 0.735 \\
\hline $\mathrm{R}^{2}$ & 0.751 & 0.746 & 0.726 & 0.699 & 0.657 \\
\hline Mean $\boldsymbol{Q}_{\boldsymbol{R} F} / \boldsymbol{Q}_{G E V}$ & 1.84 & 1.64 & 1.42 & 1.31 & 1.21 \\
\hline
\end{tabular}

It is evident from the $10-, 50$ - and 200 -year validation graphs (shown in Figs. 4, 5 and 6 respectively) that the estimated rational formula flood peaks $Q_{R F}$ tend to be larger than the GEV modelled flood peaks $Q_{G E V}$, especially for the lower magnitude floods, however, their trend-lines cross the 1:1 line at the larger flows - peaks at about $7000 \mathrm{~m}^{3} / \mathrm{s}$. This trend is also exhibited for the 20- and 100-year validation tests (the results of which are not shown here) and is confirmed in Table 5 where the average ratio of $Q_{R F} / Q_{G E V}$ across all recurrence intervals is approximately 1.5 , reducing from 1.84 for $T=10$ to 1.21 for $T=200$. This observation is to be expected since the $c$-values used to compute $Q_{R F}$, from Chow et al. (1988: 498), were generally larger than the calibrated runoff coefficients obtained in this study (see Table 2 and Fig. 3). Although the $R^{2}$-values are reasonable, the correlation is calculated in log-space and may disguise the fact that 

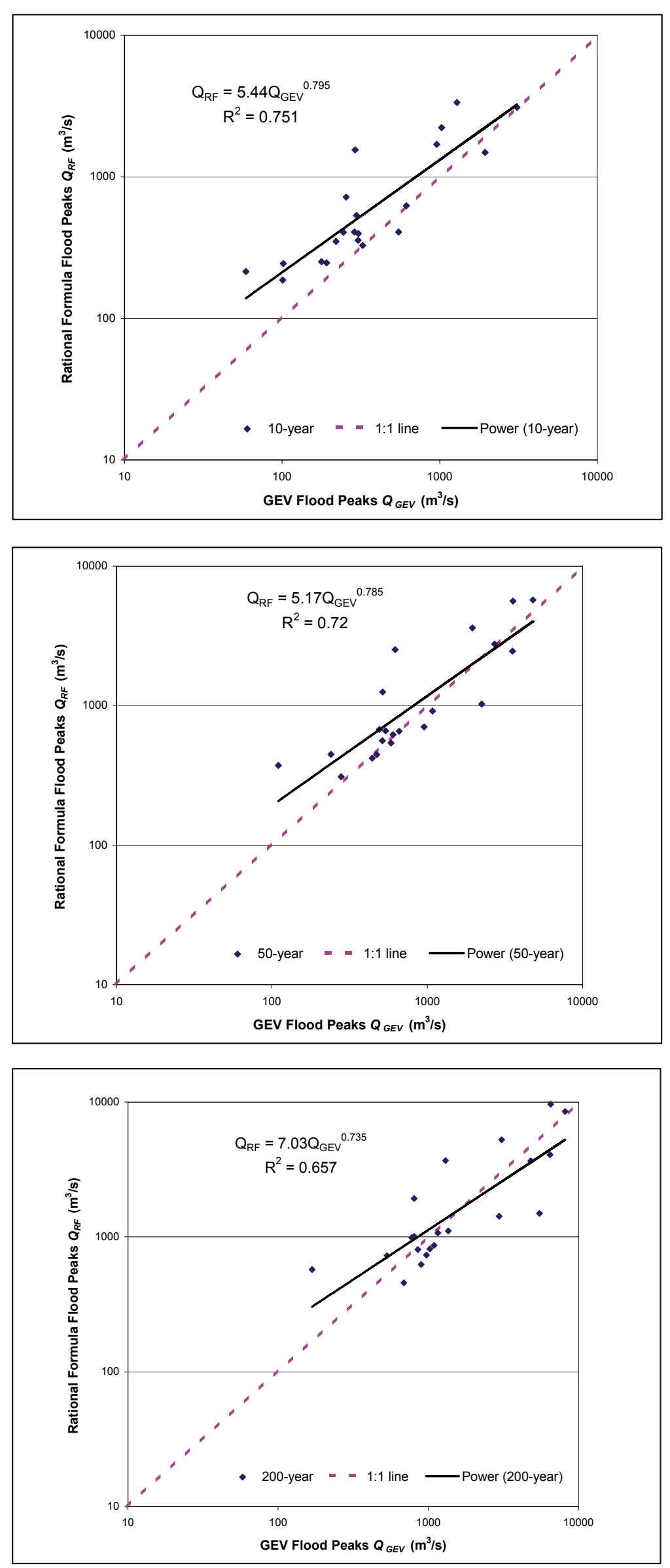

some flow peak ratios are occasionally different by up to a factor of 5 (see Table A7, Part 3 in the Appendix for the full list of values). As a consequence, the $c$-values adopted for this validation exercise, from Chow et al., were treated as trial upper bound estimates, conceding that although consistent, the method is prone to error.

\section{Discussion of results}

\section{Calibration}

Calibration of the rational formula's runoff coefficients, using runhydrograph flood peak and volume pairs of given recurrence intervals, was performed with the intention of removing the subjectivity involved in this parameter's estimation in the design environment. Use was made of characteristic $T$-year flood peak and volume pairs together with $T$-year design rainfall intensities, as a function of the catchments time of concentration, in order to obtain the coefficients. The results of this exercise produced calibrated runoff coefficients, as a function of recurrence interval, which were scattered (see Fig. 3) around published values from Chow et al. (1988: 498). The calibrated values spread around the latter set of coefficients but were, in general, lower in magnitude (bar two catchments) and had gentler growths as a function of recurrence interval. Although this result did not produce a good match, the calibrated coefficients were sensible in magnitude. However, it was worrying to note that calibrated coefficients from six catchments (of the original 29) had a tendency to decrease in magnitude with increasing recurrence interval. This deviation from the norm is attributed to the fact that the flood runoff data (calculated using the runhydrograph method) had a gentler growth curve, as a function of recurrence interval, than the design rainfall data. It was found that the fitted $c$-values could not be regionalised in agree-

\section{Figure 4 (top left)}

A graph, for the purposes of validation, showing a plot in log space of the 10-year rational formula flood peaks $Q_{R F}$ (using Chow et al.'s (1988) c-values as substitutes for calibrated runoff coefficients) vs. the 10-year GEV modelled flood peaks $Q_{G E V}$

Figure 5 (middle left)

A graph, for the purposes of validation, showing a plot in log space of the 50-year rational formula flood peaks $Q_{R F}$ (using Chow et al.'s (1988) c-values as substitutes for calibrated runoff coefficients) vs. the 50-year GEV modelled flood peaks $Q_{G E V}$

Figure 6 (bottom left)

A graph, for the purposes of validation, showing a plot in log space of the 200-year rational formula flood peaks $Q_{R F}$ (using Chow et al.'s (1988) c-values as substitutes for calibrated runoff coefficients) vs. the 200-year GEV modelled flood peaks $Q_{G E V}$ 
ment with the conclusions of Pilgrim and Cordery (1993). Thus it is confirmed that $c$ is a function of land-use, slope, $T_{c}$ (through the design storm) and $T$. The fitted $c$-values (Fig. 3) were generally lower than those suggested by Chow et al. (1988: 498); it was therefore decided to accept the latter values for the purpose of validation, conscious of this discrepancy.

\section{Hydrograph time base-length $B$}

It was initially thought that this investigation would be able to produce entire design hydrographs (albeit in an idealised triangular form) from the rational formula since the flood data used (from the runhydrograph method) described characteristic peak and volume pairs for each catchment. It was hoped that the ratio of $B$ to $T$ (effectively a ratio of $B$ to the time to peak of a rational formula hydrograph) would be consistent and that a particular outflow hydrograph could be prescribed with the use of this method. However, the results (see Table 3) indicate that, firstly, the average ratios are not constant across all recurrence intervals and, secondly, that the coefficients of variation are quite high (they range from 0.51 to 0.66 ). Also, the results shown in Table 3 exclude three catchments of area less than $130 \mathrm{~km}^{2}$ as they gave ratios in excess of seven, however, several points are worth noting.

Firstly the base-lengths are, on average, 2.25 times the catchments' time of concentration across all recurrence intervals. This result is somewhat less than the length of the hydrograph suggested by Rooseboom et al. (1981) and Alexander (2002), which was $3 T$, but Table 3 also indicates that a fair proportion of the calculated base lengths exceeded this number. As explained earlier, the hydrograph shape suggested by Rooseboom et al. (1981) was not meant to maintain continuity but was instead designed to be conservative. The hydrographs derived in this study are thus expected to have a smaller base-length as continuity is implicitly maintained, so the result is in line with expectation.

Secondly, the tendency of the base-length to increase with $\mathrm{T}$ is possibly due to the method employed by H\&F in extracting their hydrographs and the non-linearity of the rainfall runoff process (abstractions reduce with $T$ ). As depicted in Fig. 7, $\mathrm{H} \& \mathrm{~F}$ employed a truncation level for each catchment in order to extract independent hydrographs from their continuous records of streamflows. Flood volumes were obtained by extrapolating the rising limb and the recession limb of the discharge curves downwards towards zero flow from the first point below the truncation level which showed a reversal in slope. Depending on this level, a higher truncation level is likely to result in a reduction in the modelled volume when compared to the actual volume of the flood event. Thus it is likely that the base-lengths achieved in this study are smaller (as a function of $T_{c}$ ) for the smaller floods (more frequent events) than the base-lengths for the larger events, thus exhibiting the trend in Table 3.

Finally, it interesting to examine the relationship between $B$ and $T_{c}$ using a linear rainfall-runoff model as a comment on the values appearing in Table 3. If a constant (pulsed) input of rainfall of intensity $i$ (in $\mathrm{mm} / \mathrm{h}$ ) on a catchment of area $A$ (in $\mathrm{km}$ ) lasts for the time of concentration $T_{\mathrm{c}}$ (hours), the total volume of rain that falls is $V=1000 \cdot i \cdot T \cdot A\left(\mathrm{in}^{3}\right)$. The average rate of flow onto the catchment is $1000 \cdot i \cdot A\left(\right.$ in $\mathrm{m}^{3} / \mathrm{h}$ ) and the peak outflow $Q$ must be a fraction of this, say $\alpha \cdot 1000 \cdot i \cdot A\left(\mathrm{~m}^{3} / \mathrm{h}\right)$, where $0<\alpha<1$ $(\alpha$ is a factor related to the closeness of the peak to its asymptotic value as defined by its nearness to equilibrium). The baselength of the equivalent triangular hydrograph is thus $B=\mathrm{V} / \mathrm{O}=$ $2 \cdot T_{\mathrm{c}} / \alpha$ (in hours). If there are no losses, the maximum peak that occurs at $T_{\mathrm{c}}$ can only be approaching equilibrium asymptotically,

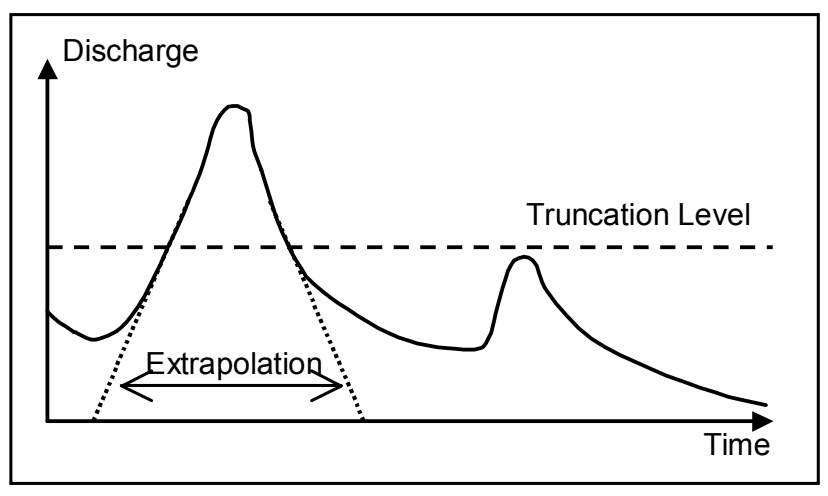

Figure 7

The method employed by Hiemstra and Francis (1979) to extract independent hydrographs from a continuous flow record, showing that a lower truncation level is likely to provide a bigger volume.

so $\alpha$ has to be chosen close to 1 . If $\alpha=0.9$, then it turns out that $B \approx 2.2 T_{\mathrm{c}}$, which is close to the average ratio (determined from Table 3 above).

\section{Validation}

The validation exercise was necessary to test whether the calibrated coefficients behaved in the probabilistic manner for which they were designed, i.e. to predict design floods of magnitudes equivalent to those derived from a statistical analysis of flood records from that site. However, since it was shown that $c$ is not dependent on physical properties nor location of the un-gauged catchments, $c$-values from Chow et al. (1988: 498), which are a function of $T$, catchment slope and land-use characteristics, were substituted for the calibrated coefficients as approximate upper bound values. Based on this substitution, the validation exercise was ultimately reduced to a test of whether the $c$-values from Chow et al. (or possibly some other summary values) could provide reasonable design flood estimates such as those obtained from a statistical distribution (such as the GEV) fit to historical flood data.

The result of this exercise showed that the floods estimated using the substitute $c$-values from Chow et al. (1988) produced floods from the rational formula that were, on average, approximately 1.5 times larger than the floods estimated from the statistical distributions of the historical data (see Table 5 and Figs. 4, 5 and 6), with a tendency to overestimate for lower flood peaks and $T$. This result is in line with expectation as the substitute $c$-values from Chow et al. (1988) were adopted as upper bound estimates. Given that, in order to make use of the coefficients of Chow et al., a crude matching of land coverage types was performed (see Table 4), this result is relatively pleasing especially since the catchments used in validation ranged in size from small to large (170 to $24000 \mathrm{~km}^{2}$ - see Table A7). The precision of the method is of course still low, as indicated by the spread of results in Figs. 4, 5 and 6, and relies heavily on the judgement of the practitioner

\section{Conclusion}

The rational formula, which is possibly the simplest rainfallrunoff flood estimation technique available was reviewed by means of calibrating the most uncertain variable of the formula, i.e. the runoff coefficient $c$. The "data set" used to achieve this was the set of runhydrographs produced by Hiemstra and 
Francis (1979). The results of the calibration were reasonably encouraging, producing $c$-coefficients that were scattered around, but generally lower than, those offered by Chow et al. (1988: 498), whose precision is not known. It was discovered that the fitted $c_{(T T C)}$-coefficients of this investigation did not show any variation with catchment characteristics, in line with Australian experience (Pilgrim and Cordery, 1993), and hence validation of these values at other sites was only possible using land-use and average slope of validation catchments together with recurrence interval as guides for the choice of $c$-values. It was thus decided to use the $c$-values from Chow et al. as approximate upper bound estimates of the fitted $c_{\text {T) }}$-coefficients in validation. In order to use their values, a match of land coverage types was required. The results of the validation were as expected, producing floods from the rational formula that were on average 1.5 times larger than the floods estimated from a statistical analysis of the validation set (not used for calibration), but with a wide scatter. Of minor importance, it was discovered that the time base-lengths of the derived triangular hydrographs of this investigation were approximately between 1.9 and 2.6 times the catchment's time of concentration, depending on the recurrence interval of the flood, lower than suggested elsewhere. It can be concluded, from the results of this investigation, that the rational formula is a simple, consistent, approximate tool when used in its probabilistic frame-work and although not suitable as a stand-alone design tool for flood estimation, can be useful as a quick check method for calculating flood hydrographs for large catchments as it is for small.

\section{Acknowledgements}

The first author would like to acknowledge the post-graduate funding provided by the South African Department of Transport, which made this research towards improved design flood estimation techniques possible.

\section{References}

ADAMSON PT (1981) Southern African Storm Rainfall. Tech. Rep. TR102. Department of Water Affairs, Pretoria.

ALEXANDER WJR (1990) Flood Hydrology for Southern Africa. SANCOLD, Pretoria

ALEXANDER WJR (2002) The Standard Design Flood - Theory and Practice. Report, Dept of Civil Engineering, University of Pretoria, Pretoria.

BASSON MS, ALLEN RB, PEGRAM GGS and VAN ROOYEN JA (1994) Probabilistic Management of Water resource and Hydropower Systems. Water Resources Publications, Colarado.

CHOW VT, MAIDMENT DR and MAYS LR (1988) Applied Hydrology. McGraw-Hill, New York.
DE MICHELE D, SALVADORI G, CANOSSI M, PETACCIA A and ROSSO R (2005) Bivariate statistical approach to check adequacy of dam spillway. J. Hydrol. Eng. ASCE 10 (1) 50-57.

FRANCIS DM (1979) The Runhydrograph Applied. M.Sc. Thesis. Dept. of Civil Engineering, University of Natal, Durban.

FSR (1975) Flood Studies Report. Vol. 2 Meteorological Studies. Natural Environment Research Council, London.

GÖRGENS AHM (2002) Design Flood Hydrology. Design and Rehabilitation of Dams. G Basson (ed.) Institute for Water and Environmental Engineering, Department of Civil Engineering, University of Stellenbosch, South Africa. 460-524.

HIEMSTRA LAV (1972) Runhydrographs - A new technique in hydrograph generation. Proc. Int. Symp. on Modelling Techniques in Water Resources Systems. Ottawa, Canada. 1 205-214.

HIEMSTRA LAV (1973) Runhydrographs for the sizing of dam spillways and the minimum reservoir capacities. Proc. International Commission on Large Dams. Madrid, Spain, 1 217-237.

HIEMSTRA LAV (1974) Runhydrographs from Poisson-generated run lengths. J. Hydraul. Div. ASCE 100 1617-1630.

HIEMSTRA LAV and FRANCIS DM (1979) The Runhydrograph - Theory and Application for Flood Predictions. Water Research Commission, Pretoria.

HIEMSTRA LAV, ZUCCHINI WS and PEGRAM GGS (1976) A method of finding the family of runhydrographs for given return periods. J. Hydrol. 30 95-103.

HRU REPORT NO. 1/72 (1972) Design Flood Determination in South Africa. DC Midgley (ed.) Hydrological Research Unit, Department of Civil Engineering, University of Witwatersrand, South Africa.

INSTITUTE OF ENGINEERS AUSTRALIA (1987) Australian Rainfall and Runoff: A Guide to Flood Estimation. DH Pilgrim (ed.) Canberra, Australia.

KIRPICH ZP (1940) Time of concentration of small agricultural watersheds. Civ. Eng. 10 (6) 362.

KOVAĆS Z (1988) Regional Maximum Flood Peaks in Southern Africa. Tech. Rep. TR 137, Department of Water Affairs, Pretoria.

PEGRAM GGS (2003) Rainfall, rational formula and regional maximum flood - some scaling links. Keynote Paper. Aust. J. Water Resour. 7 (1) 29-39.

PEGRAM GGS and PARAK M (2004) A review of the regional maximum flood and rational formula using geomorphological information and observed floods. Water SA 30 (3) 377-392.

PETRAS V and DU PLESSIS PH (1987) Catalogue of Hydrological Parameters. Flood Studies. Technical Note No. 6, Department of Water Affairs, Pretoria.

PILGRIM DH and CORDERY I (1993) Chapter 9: Flood Runoff. In: DR Maidment (ed.) Handbook of Hydrology. McGraw-Hill, New York.

ROOSEBOOM A, BASSON MS, LOOTS CH, WIGGET JH and BOSMAN J (1981) National Transport Commission Road Drainage Manual (1stedn.) National Transport Commission, Directorate Land Transport, Pretoria.

SMITHERS JC and SCHULZE RE (2002) Design Rainfall and Flood Estimation in South Africa. WRC Report 1060/1/03, Water Research Commission, South Africa. 


\section{APPENDIX}

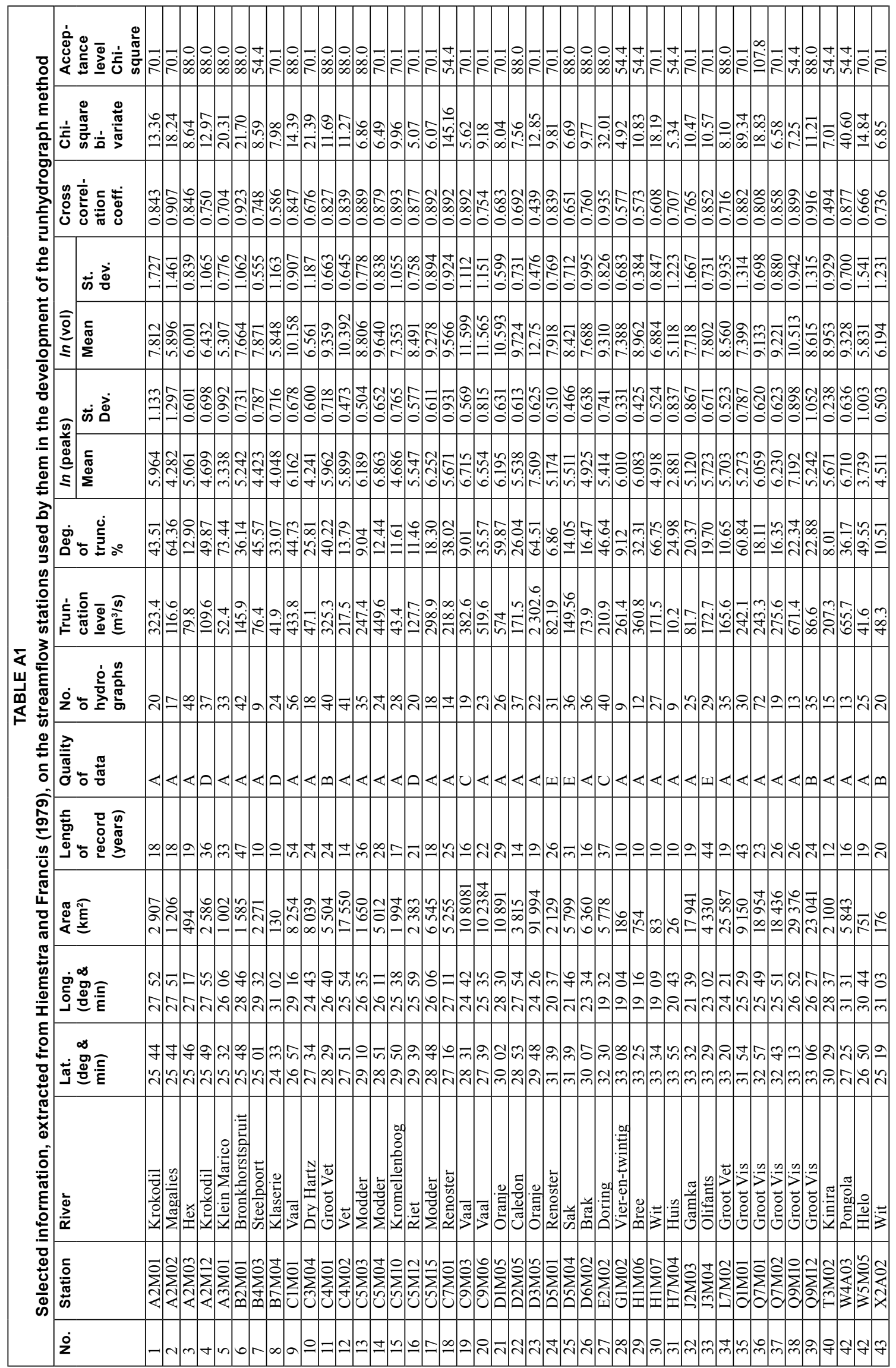




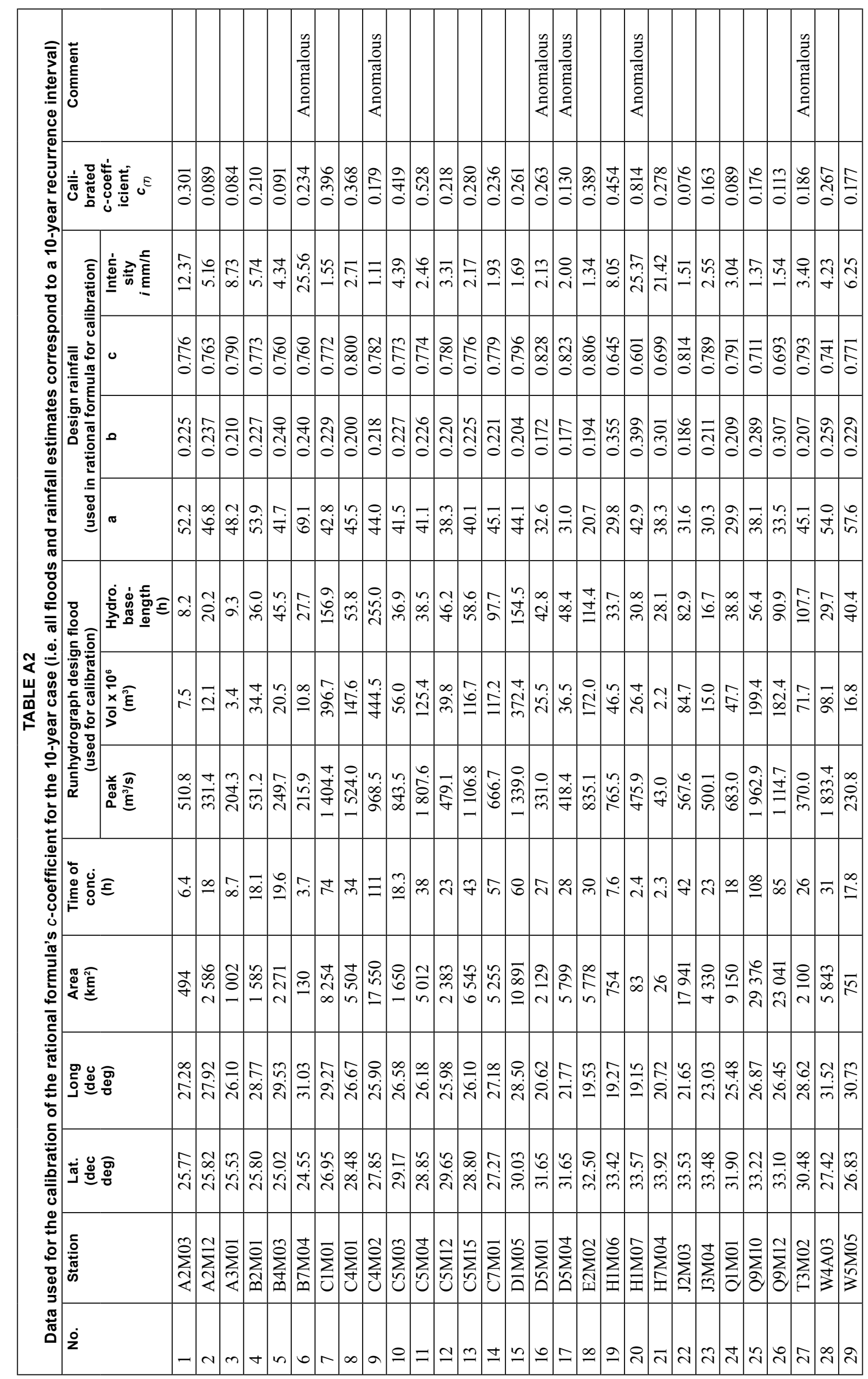




\begin{tabular}{|c|c|c|c|c|c|c|c|c|c|c|c|c|c|c|c|c|c|c|c|c|c|c|c|c|c|c|c|c|}
\hline & 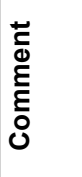 & & & & & & & 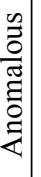 & & & & & & & & & 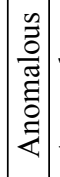 & 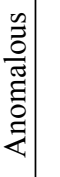 & & 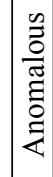 & & & & & & & & \\
\hline & 㐫 & ن & 色 & ô. & Oे & 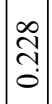 & $\frac{\mathrm{c}}{0}$ & 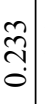 & $\frac{8}{\vec{\sigma}}$ & & & & 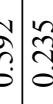 & $\begin{array}{l}\text { Dे } \\
\text { ñ } \\
0\end{array}$ & 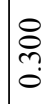 & : & 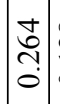 & 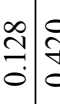 & & $\mid \begin{array}{l}8 \\
\infty \\
0 \\
0\end{array}$ & 鿖 & 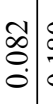 & 文 & & $\begin{array}{c}\vec{y} \\
\vdots \\
\end{array}$ & & & $\frac{\hat{\sigma}}{0}$ \\
\hline & 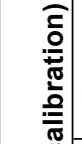 & 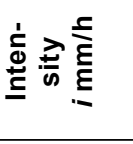 & $\stackrel{\text { ले }}{\stackrel{ \pm}{-}}$ & $\begin{array}{l}\infty \\
0 \\
0 \\
0\end{array}$ & $\mid \begin{array}{l}\stackrel{\bullet}{0} \\
\dot{\Theta}\end{array}$ & & $\begin{array}{l}\stackrel{\rho}{\dot{\sigma}} \\
\dot{r}\end{array}$ & ले & . & $\underset{c}{m} \mid$ & $\stackrel{\infty}{\stackrel{\infty}{\sim}}$ & 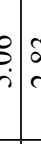 & 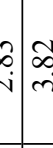 & $\begin{array}{l}n \\
\vdots \\
i\end{array}$ & 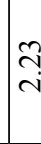 & $\stackrel{\infty}{=}$ & $\left|\begin{array}{c}\tilde{n} \\
\text { in }\end{array}\right|$ & $\begin{array}{c}0 \\
\\
\end{array}$ & $\overbrace{0}^{2}$ & $\mid \begin{array}{l}\mathcal{C} \\
\substack{\infty \\
\sim}\end{array}$ & $\mid \begin{array}{c}a \\
\\
\end{array}$ & 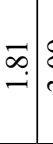 & & $\vec{n}$ & $:$ & & $\mid \begin{array}{l}0 \\
i \\
\text { in }\end{array}$ & 1 \\
\hline 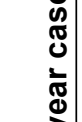 & 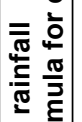 & 0 & $\stackrel{0}{2}$ & $\begin{array}{l}0 \\
0 \\
0 \\
0\end{array}$ & $\begin{array}{l}2 \\
2 \\
0 \\
0\end{array}$ & $\begin{array}{l}2 \\
\stackrel{2}{0} \\
0\end{array}$ & $\begin{array}{l}8 \\
\stackrel{0}{0} \\
0\end{array}$ & $\begin{array}{l}8 \\
\stackrel{0}{0} \\
0\end{array}$ & \begin{tabular}{l}
$\mathbb{1}$ \\
\multirow{2}{0}{} \\
0
\end{tabular} & 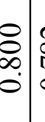 & 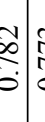 & 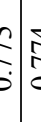 & $\underbrace{\infty}_{\substack{0 \\
0}}$ & : & 20 & $\stackrel{2}{2}$ & $\left|\begin{array}{c}\infty \\
0 \\
0 \\
0 \\
0\end{array}\right|$ & \begin{tabular}{ccc}
$\widetilde{1}$ & \multicolumn{1}{c}{} \\
0 & $\alpha$ \\
0 & 0 & 0
\end{tabular} & : & $\begin{array}{l}\bar{b} \\
0 \\
0 \\
0\end{array}$ & o. & 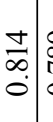 & 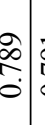 & 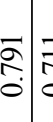 & $=0$ & & & $\pi$ \\
\hline 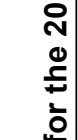 & $\mid$ & مـ & 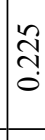 & 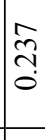 & 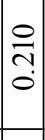 & 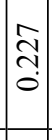 & 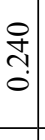 & 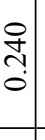 & స్. & 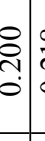 & & & 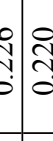 & î & స్ & ì & $\mid$\begin{tabular}{c}
0 \\
\hdashline \\
\hdashline
\end{tabular} & \begin{tabular}{ll}
5 \\
\hdashline \\
0
\end{tabular} & 5 & ?. & $\mid \begin{array}{l}0 \\
0 \\
0 \\
0\end{array}$ & $\begin{array}{l}\circ \\
0 \\
0\end{array}$ & $\begin{array}{c}\overline{\mathrm{\sigma}} \\
\text { o. }\end{array}$ & 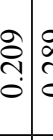 & 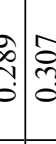 & & $\mid \begin{array}{l}\hat{\imath} \\
\text { ஸे }\end{array}$ & సे \\
\hline 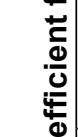 & 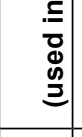 & & & 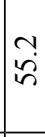 & $\begin{array}{l}0 \\
\dot{n} \\
i \\
\mid\end{array}$ & $\hat{j}$ & 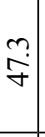 & $\underset{\infty}{\stackrel{N}{\Delta}}$ & $\begin{array}{l}\dot{0} \\
\dot{q}\end{array}$ & in & 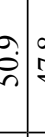 & : & $?$ & 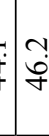 & in & $\frac{\partial}{n}$ & $\mid \begin{array}{c}0 \\
\infty \\
m\end{array}$ & $\begin{array}{lll}0 \\
\dot{ల}\end{array}$ & 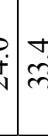 & $\begin{array}{c}\vec{b} \\
\dot{\alpha} \\
\dot{\alpha}\end{array}$ & $\begin{array}{l}+ \\
\dot{b} \\
\dot{b}\end{array}$ & $\stackrel{\text { m. }}{m}$ & : & $\begin{array}{lll}0 & \\
\dot{m} & \end{array}$ & $\begin{array}{l}? \\
\dot{y} \\
\dot{y}\end{array}$ & & fi & 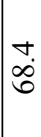 \\
\hline 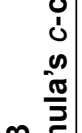 & 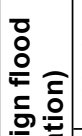 & 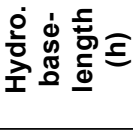 & $\infty$ & ते & $\mid \begin{array}{l}\infty \\
\infty \\
\infty\end{array}$ & 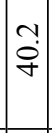 & $\begin{array}{l}\stackrel{\vec{g}}{\mathrm{~g}} \\
\end{array}$ & : & $\begin{array}{l}0 \\
0 \\
0 \\
0 \\
-1\end{array}$ & : & $\begin{array}{c}\text { : } \\
: \\
:\end{array}$ & $=$ & $\underset{f}{q}$ & fi & 宁 & $\begin{array}{l}\sim \\
\tilde{n}\end{array}$ & $\mid \begin{array}{l}\infty \\
\dot{b} \\
\dot{f}\end{array}$ & $\begin{array}{lll}n & 7 \\
& 7\end{array}$ & $\stackrel{m}{\infty}$ & $\begin{array}{l}\infty \\
i \\
i\end{array}$ & $\vec{i}$ & : & $\stackrel{\square}{=}$ & $\begin{array}{l}0 \\
\dot{q} \\
\dot{f}\end{array}$ & 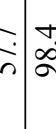 & & 官. & 8 \\
\hline 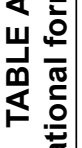 & 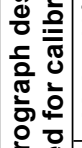 & 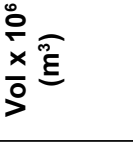 & 2 & 象 & $\overrightarrow{+}$ & $\begin{array}{l}m \\
\dot{q}\end{array}$ & $\left|\begin{array}{c}\stackrel{2}{*} \\
\dot{\sim}\end{array}\right|$ & $\exists$ & : & $\begin{array}{l}\infty \\
\\
=\end{array}$ & त) & 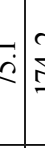 & $\begin{array}{l} \pm \\
\pm\end{array}$ & : & $\stackrel{?}{I}$ & $\begin{array}{l}n \\
\infty \\
y\end{array}$ & ले & ๖े & $\frac{a}{n}$ & $\frac{\stackrel{c}{m}}{m}$ & $\stackrel{m}{m}$ & $\stackrel{\Xi}{\dot{\Xi}}$ & : & $\underset{\tau}{*}$ & ה: & & & : \\
\hline 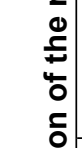 & 资 & 递高 & 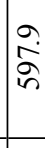 & 年 & $\mid \begin{array}{l}0 \\
0 \\
\infty \\
i \\
i \\
\end{array}$ & $\begin{array}{l}n \\
0 \\
0 \\
0\end{array}$ & 空 & 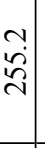 & $\begin{array}{l}\hat{\dot{a}} \\
\mathrm{a} \\
-\end{array}$ & $\begin{array}{c}\infty \\
\dot{\vec{g}} \\
\infty \\
-\end{array}$ & $\begin{array}{l}n \\
\vdots \\
\vdots \\
0 \\
0\end{array}$ & 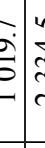 & 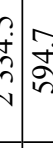 & $\stackrel{n}{\underset{+}{m}}$ & ๑ & ? & $\begin{array}{l}0 \\
\text { ले } \\
\text { ले }\end{array}$ & 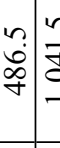 & 字 & $\begin{array}{l}0 \\
\dot{d} \\
i \\
n\end{array}$ & $\stackrel{\vec{r}}{i}$ & 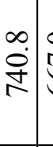 & : & 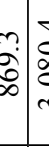 & 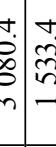 & & & वें \\
\hline$\frac{\sqrt[\pi]{0}}{\frac{0}{\pi}}$ & 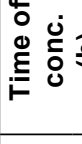 & & ְै. & $\infty$ & $\stackrel{-}{\infty}$ & $\vec{\infty}$ & {$\left[\begin{array}{l}0 \\
:\end{array}\right]$} & $\vec{m}$ & \pm & $\dot{m}$ & $\exists$ & $\begin{array}{c}n \\
0 \\
0 \\
0\end{array}$ & 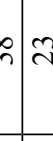 & $\mathscr{F}$ & in & 8 & $\hat{\sim}$ & 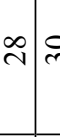 & 2 & $\stackrel{\vec{\Delta}}{\stackrel{\vec{i}}{*}}$ & $\stackrel{m}{i}$ & F) & 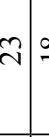 & $\left.\infty\right|_{\infty} ^{\infty}$ & $\begin{array}{c}\infty \\
0 \\
0\end{array}$ & & & 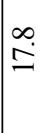 \\
\hline 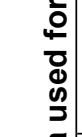 & 离 & & $\underset{\sigma}{\sigma}$ & $\mid \begin{array}{l}\infty \\
\infty \\
\sim \\
\sim\end{array}$ & 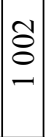 & & $\mid \begin{array}{l}\vec{\lambda} \\
\vec{v}\end{array}$ & 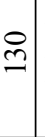 & \begin{tabular}{ll}
\multirow{2}{*}{} \\
\multirow{2}{*}{} \\
$\infty$
\end{tabular} & 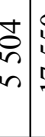 & 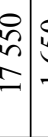 & $\begin{array}{c}0 \\
6 \\
6\end{array}$ & 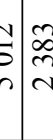 & $\begin{array}{l}1 \\
\vdots \\
4 \\
0\end{array}$ & & $\begin{array}{l}\bar{a} \\
\infty\end{array}$ & $\begin{array}{l}\text { సे } \\
\text { ते }\end{array}$ & 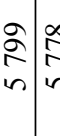 & 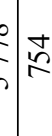 & $\infty$ & 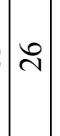 & 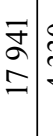 & 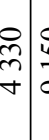 & \begin{tabular}{lll}
8 & 0 \\
\hdashline & 0
\end{tabular} & 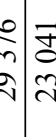 & & & $\sqrt{2}$ \\
\hline & 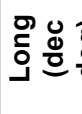 & & 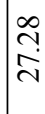 & 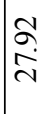 & & $\begin{array}{c}\hat{2} \\
\infty \\
\sim \\
\sim\end{array}$ & $\mid \begin{array}{l}\tilde{n} \\
\hat{\imath} \\
\vdots\end{array}$ & $\frac{\tilde{m}}{\dot{m}}$ & $\begin{array}{l}\text { ते } \\
\text { הิ }\end{array}$ & & $\begin{array}{c}8 \\
c \\
c\end{array}$ & 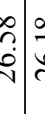 & 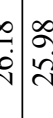 & \begin{tabular}{l}
0 \\
0 \\
\hdashline
\end{tabular} & & $\begin{array}{l}\infty \\
\infty \\
\infty \\
i\end{array}$ & 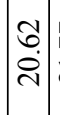 & 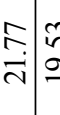 & $\stackrel{\overbrace{}}{\triangle}$ & $\frac{n}{2}$ & 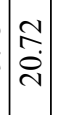 & $\begin{array}{l}n \\
\dot{\sim} \\
\vec{N}\end{array}$ & ç: & 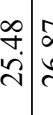 & 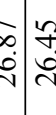 & & & 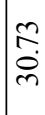 \\
\hline & $\dot{\square}$ & & $\begin{array}{l}\hat{\imath} \\
\hat{n}\end{array}$ & $\begin{array}{l}0 \\
\infty \\
\ddot{2}\end{array}$ & $\mid \begin{array}{l}n \\
n \\
n \\
n\end{array}$ & $\begin{array}{l}0 \\
\infty \\
i \\
i\end{array}$ & $\mid$ & $\begin{array}{l}n \\
\tilde{n} \\
\stackrel{n}{2}\end{array}$ & 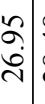 & $\begin{array}{l}\infty \\
\infty \\
\infty \\
c \\
c\end{array}$ & is & $=$ & 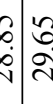 & $\begin{array}{l}\infty \\
\substack{\infty \\
\infty \\
\infty}\end{array}$ & & ồ & $\mid \begin{array}{c}\hat{\sigma} \\
\dot{m}\end{array}$ & 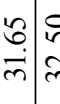 & $\frac{7}{m}$ & $\begin{array}{l}n \\
\tilde{n} \\
m \\
m\end{array}$ & ले & ભి & $\begin{array}{c}\infty \\
\dot{n} \\
\dot{c}\end{array}$ & 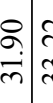 & $\begin{array}{c}n \\
\dot{n}\end{array} \frac{0}{m}$ & & & 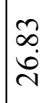 \\
\hline & 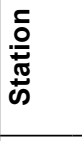 & & 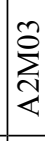 & $\underset{\sum}{\stackrel{N}{Z}}$ & $\sum_{\substack{\infty \\
\gtrless}}^{\bar{s}}$ & $\begin{array}{c}\overline{0} \\
\stackrel{\lambda}{n} \\
\end{array}$ & 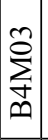 & $\sum_{\substack{ \pm\\
}}^{+}$ & $\sum_{0}^{0}$ & $\sum_{0}^{0}$ & J & $\begin{array}{l}0 \\
3 \\
3\end{array}$ & $\sum_{\substack{0 \\
0}}$ & $\sum_{i=0}^{n}$ & $\sum_{0}^{0}$ & $\sum^{\infty}$ & $\sum_{\hat{n}}^{\vec{a}}$ & 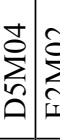 & 这 & 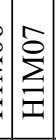 & 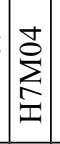 & $\sum_{\substack{0 \\
0}}^{\infty}$ & 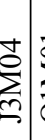 & 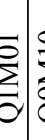 & $\frac{0}{2} \sum_{2}^{2}$ & 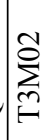 & 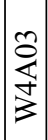 & $\sum_{\substack{n \\
i \\
i}}^{\infty}$ \\
\hline & & & & & & + & & 6 & $r$ & $\infty$ & & $=$ & $=$ & 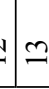 & & - & 10 & $=9$ & $=-1$ & $\stackrel{\imath}{\wedge}$ & $\bar{\sim}$ & i] & $\therefore$ & $\stackrel{\Delta}{\sim} \mid$ & i) & 12 & $\stackrel{\infty}{\sim}$ & \\
\hline
\end{tabular}




\begin{tabular}{|c|c|c|c|c|c|c|c|c|c|c|c|c|c|c|c|c|c|c|c|c|c|c|c|c|c|c|c|c|c|}
\hline & 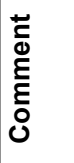 & & & & & & & 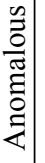 & & & 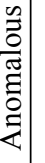 & & & & & & & 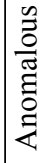 & & & 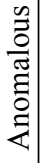 & & & & & & 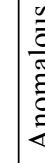 & & \\
\hline & 造 & ن & d & 角 & $\stackrel{0}{\circ}$ & 辛 & $\stackrel{7}{\exists}$ & $\begin{array}{c}\stackrel{5}{\mathrm{~s}} \\
0\end{array}$ & $\begin{array}{l}\text { 莳 } \\
0 \\
0\end{array}$ & $\begin{array}{l}0 \\
\dot{q} \\
0 \\
0\end{array}$ & 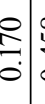 & & & $\widehat{c}$ & & 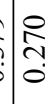 & d & & o. & 苟 & $\begin{array}{l}\stackrel{2}{\circ} \\
\vdots \\
0\end{array}$ & లి & $\begin{array}{l}0 \\
8 \\
0\end{array}$ & & 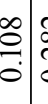 & & $\stackrel{5}{0}$ & & $\stackrel{1}{\stackrel{2}{0}}$ \\
\hline & 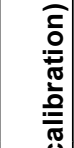 & 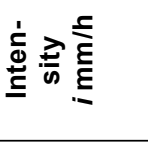 & $\stackrel{\vec{N}}{I}$ & $\underset{.}{\stackrel{F}{\sim}}$ & $\stackrel{\mathscr{\infty}}{\stackrel{\infty}{=}}$ & $\stackrel{\infty}{\infty}$ & 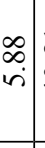 & $\begin{array}{l}\vec{a} \\
\dot{q} \\
\dot{q}\end{array}$ & $\begin{array}{l}\stackrel{m}{i} \\
\vec{i}\end{array}$ & . & $\sqrt{n}$ & : & $\begin{array}{l}t \\
\vdots \\
\vdots\end{array}$ & $\begin{array}{l}b \\
f\end{array}$ & $\hat{i}$ & $\hat{n}$ & 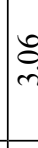 & & 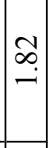 & $\begin{array}{l}\hat{y} \\
0 \\
0\end{array}$ & $\begin{array}{c}\infty \\
\infty \\
i \\
i \\
\end{array}$ & 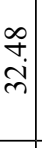 & $\begin{array}{c}\mathbf{N} \\
\mathbf{i}\end{array}$ & & $\stackrel{+}{\rightarrow}$ & & $\overline{\mathrm{i}}$ & & $\frac{n}{a}$ \\
\hline $\begin{array}{l}\mathscr{n} \\
\mathbb{8} \\
\frac{5}{\pi} \\
0\end{array}$ & 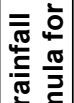 & 0 & 总 & $\begin{array}{l}0 \\
0 \\
0 \\
0\end{array}$ & ڤ̊ & 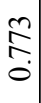 & $\begin{array}{l}8 \\
\vdots \\
0\end{array}$ & $\begin{array}{l}0 \\
\vdots \\
\vdots\end{array}$ & 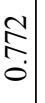 & 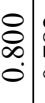 & 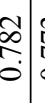 & 0 & 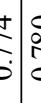 & 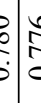 & $: \frac{1}{5}$ & $\frac{2}{2}$ & $\begin{array}{l}\infty \\
\infty \\
\infty \\
0\end{array}$ & 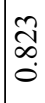 & $\begin{array}{l}0 \\
8 \\
0 \\
0\end{array}$ & : & : & : & $\begin{array}{l} \\
\\
0 \\
\end{array}$ & & $\overrightarrow{\hat{\sigma}}$ & & $\left\{\begin{array}{l}0 \\
0 \\
0\end{array}\right.$ & & $\underset{i}{i}$ \\
\hline $\begin{array}{l}0 \\
0 \\
0 \\
0 \\
5 \\
5 \\
0\end{array}$ & 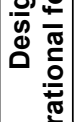 & م & 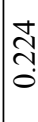 & 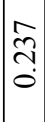 & $\frac{0}{\sqrt{n}}$ & הָ & $\begin{array}{l}\stackrel{o}{+} \\
\stackrel{0}{0}\end{array}$ & ڤેे & 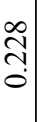 & ڤి. & $\begin{array}{c}\infty \\
\stackrel{2}{0} \\
\vdots \\
\end{array}$ & 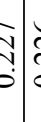 & & ปे & ปิ & 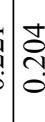 & $\frac{1}{0}$ & $\stackrel{5}{0}$ & $\frac{+}{2}$ & ڤ̂े & के & ర్ల. & $\begin{array}{l}\infty \\
\stackrel{\infty}{0} \\
0\end{array}$ & है: & 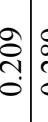 & & 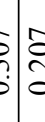 & & సิ \\
\hline 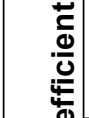 & $\begin{array}{l}. \bar{Z} \\
\bar{d} \\
0 \\
\underline{9} \\
\end{array}$ & $\sigma$ & $\begin{array}{l}0 \\
i \\
i\end{array}$ & $\begin{array}{l}0 \\
\frac{\pi}{6}\end{array}$ & \begin{tabular}{l}
$m$ \\
\hdashline \\
\hdashline
\end{tabular} & $\begin{array}{l}\sim \\
\infty \\
\infty\end{array}$ & $\stackrel{t}{\dot{b}}$ & $\stackrel{m}{0}$ & $\begin{array}{l}\dot{a} \\
\infty \\
\infty \\
\end{array}$ & : & 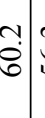 & $?$ & $\dot{6}$ & 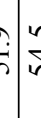 & $\frac{0}{6}$ & 它 & $\begin{array}{l}9 \\
6 \\
7\end{array}$ & $\stackrel{\sim}{\mathscr{f}}$ & 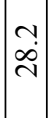 & $\left|\begin{array}{c}0 \\
\dot{\infty} \\
m\end{array}\right|$ & in & $\vec{\infty}$ & oे & aे & :े. & & $\begin{array}{c}8 \\
0\end{array}$ & & $\stackrel{m}{\infty}$ \\
\hline $\begin{array}{c}0 \\
0 \\
0 \\
i \\
\frac{0}{5}\end{array}$ & $\begin{array}{l}\bar{z} \\
\vdots \\
\frac{0}{4} \\
5 \\
0.0\end{array}$ & 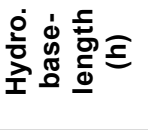 & $\approx$ & $\begin{array}{l}m \\
2 \\
i\end{array}$ & 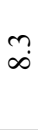 & $\begin{array}{l}0 \\
\dot{q} \\
\dot{q}\end{array}$ & $\overrightarrow{\dot{m}}$ & $\begin{array}{l}\infty \\
\dot{m} \\
\dot{m}\end{array}$ & $\underset{\substack{0 \\
\infty}}{\dot{\Phi}}$ & $\vec{i}$ & 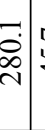 & fo & $\dot{f}$ & $\hat{n}$ & i & $\frac{0}{n}$ & $\frac{0}{n}$ & ? & 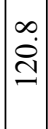 & $\left|\begin{array}{c}\hat{i} \\
\hat{m}\end{array}\right|$ & 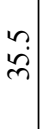 & $\begin{array}{c}\mathfrak{c} \\
\stackrel{m}{2}\end{array}$ & 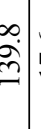 & $\stackrel{?}{=}$ & $\stackrel{\infty}{\substack{\infty\\
}}$ & & 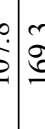 & & $\stackrel{l}{\circ}$ \\
\hline 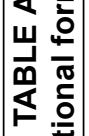 & 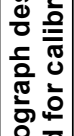 & 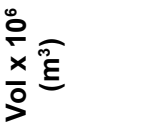 & $\overline{\mathrm{I}}$ & $\vec{\sim}$ & $\overrightarrow{i n}$ & 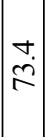 & $\stackrel{?}{\grave{2}}$ & 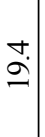 & $\begin{array}{l}\infty \\
\stackrel{\dot{q}}{2}\end{array}$ & $\begin{array}{l}n \\
\cdots \\
\end{array}$ & 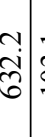 & 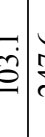 & 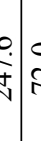 & ن. & 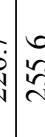 & ì & 年 & $\frac{m}{n}$ & $\begin{array}{l}\stackrel{0}{\vec{i}} \\
\stackrel{\mathrm{N}}{1}\end{array}$ & $\mid \begin{array}{l}\infty \\
\infty \\
i \\
i\end{array}$ & $\begin{array}{c}\stackrel{N}{d} \\
\infty \\
m\end{array}$ & mi & 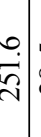 & & 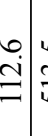 & & $\frac{\infty}{9}$ & & $\stackrel{\infty}{\infty}$ \\
\hline 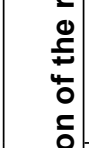 & 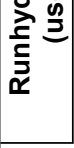 & 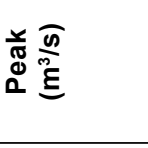 & $\underset{\infty}{\stackrel{\infty}{\infty}}$ & $\begin{array}{l}2 \\
\stackrel{2}{0} \\
i n\end{array}$ & 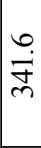 & $\begin{array}{l}0 \\
\dot{a} \\
\infty \\
\infty\end{array}$ & $\begin{array}{l}\dot{0} \\
\dot{0} \\
\forall\end{array}$ & $\hat{s}$ & 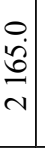 & 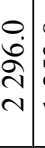 & 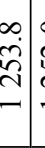 & 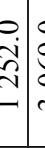 & $=$ & 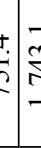 & 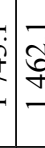 & $\begin{array}{l}\infty \\
\infty \\
2\end{array}$ & $\begin{array}{l}\infty \\
\infty \\
\infty \\
\forall\end{array}$ & 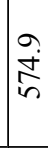 & $\begin{array}{l}n \\
\infty \\
\infty \\
m \\
-1\end{array}$ & $\mid \begin{array}{l}\dot{y} \\
\dot{\alpha} \\
\text { aे }\end{array}$ & $\left|\begin{array}{l}0 \\
\infty \\
\infty \\
i \\
i n\end{array}\right|$ & 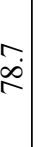 & مू & b & 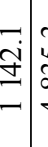 & & ș & & 辛 \\
\hline 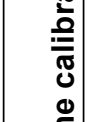 & 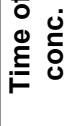 & & ఠ઼. & $\infty$ & $\ddot{\infty}$ & $-\vec{\infty}$ & $\begin{array}{l}0_{1} \\
\stackrel{9}{\mid} \mid\end{array}$ & & \pm & $\stackrel{m}{m}$ & $\Xi$ & 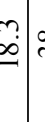 & $\stackrel{2}{\circ}$ & $\mathrm{S}$ & & 8 & $\hat{\imath}$ & & in & $\stackrel{0}{\longrightarrow}$ & $\stackrel{\vec{i}}{\mathrm{i}}$ & $\stackrel{?}{i}$ & $\underset{F}{F}$ & & $\infty$ & & 0 & & $\stackrel{\infty}{=}$ \\
\hline 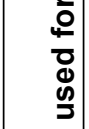 & 离 & & $\stackrel{+}{a}$ & $\mid \begin{array}{l}\infty \\
\infty \\
2 \\
\sim\end{array}$ & $\stackrel{\tilde{o}}{-}$ & $\begin{array}{l}\mathscr{n} \\
\infty \\
n \\
-1\end{array}$ & $\underset{\sim}{\vec{N}}$ & 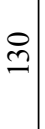 & 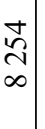 & $\begin{array}{c}\vec{b} \\
\text { ch } \\
n\end{array}$ & $\begin{array}{l}8 \\
n \\
n \\
=\end{array}$ & 8 & & 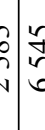 & {$\left[\begin{array}{l}n \\
\text { in } \\
\text { in }\end{array}\right.$} & & $\stackrel{2}{\stackrel{I}{N}}$ & $\begin{array}{l}2 \\
\hat{2} \\
i n\end{array}$ & 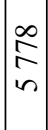 & 弆 & $\tilde{\infty}$ & $\underset{\sim}{~}$ & I & 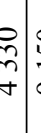 & $\frac{1}{a}$ & & $\stackrel{8}{7}$ & & $\vec{n}$ \\
\hline & 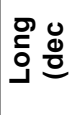 & & $\stackrel{\infty}{\stackrel{\infty}{N}}$ & $\stackrel{\grave{\sim}}{\grave{\sim}}$ & 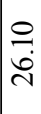 & $\begin{array}{c}\hat{N} \\
\infty \\
\infty \\
\sim\end{array}$ & $\mid \begin{array}{l}n \\
\hat{n} \\
\hat{i}\end{array}$ & $\mid \begin{array}{c}\tilde{\rho} \\
\dot{m} \\
\end{array}$ & 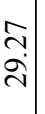 & 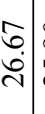 & $\begin{array}{l}8 \\
\text { à }\end{array}$ & 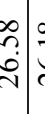 & $\begin{array}{l}8 \\
\dot{s} \\
0\end{array}$ & $\stackrel{8}{c}$ & $\stackrel{\infty}{\lambda}$ & 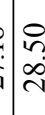 & రీ & $\stackrel{\stackrel{ }{i}}{\vec{v}}$ & $\begin{array}{l}\tilde{2} \\
\stackrel{-}{2}\end{array}$ & $\begin{array}{l}\hat{\imath} \\
\stackrel{2}{=}\end{array}$ & $\stackrel{n}{9}$ & î. & $\frac{b}{n}$ & & c) & & $\stackrel{b}{b}$ & & 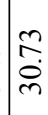 \\
\hline & & & શે & $\begin{array}{l}\infty \\
\infty \\
\infty \\
\\
\end{array}$ & $\begin{array}{l}\hat{n} \\
\\
\end{array}$ & $\begin{array}{l}\infty \\
\infty \\
0 \\
\\
\end{array}$ & 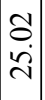 & $\left|\begin{array}{l}n \\
\stackrel{n}{\sim} \\
i\end{array}\right|$ & 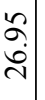 & $\begin{array}{c}\infty \\
\substack{0 \\
\infty \\
\sim} \\
\mid\end{array}$ & 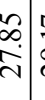 & 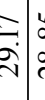 & $\begin{array}{lll}6 \\
\dot{y} \\
\dot{y}\end{array}$ & 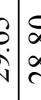 & $: \begin{array}{l}\hat{2} \\
\vdots \\
\vdots\end{array}$ & $\begin{array}{l}n \\
0 \\
0\end{array}$ & $\frac{\approx}{m}$ & $\frac{n}{m}$ & $\begin{array}{l}\stackrel{2}{n} \\
i \\
m\end{array} \mid$ & $\begin{array}{c}\mathcal{F} \\
\tilde{m} \\
\tilde{m}\end{array}$ & $\mid \begin{array}{l}n \\
n \\
m \\
m\end{array}$ & 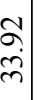 & $\tilde{n}$ & & 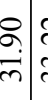 & & 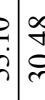 & & $\begin{array}{l}\infty \\
\infty \\
\dot{N}\end{array}$ \\
\hline & 竞 & & $\sum_{\gtrless}^{0}$ & 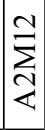 & 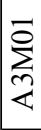 & 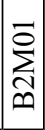 & $\sum_{\substack{\infty \\
\infty \\
\infty}}^{\infty}$ & $\sum_{\substack{0 \\
\infty}}^{0}$ & $\sum_{0}^{\vec{a}}$ & $\sum_{0}^{\infty}$ & $\sum_{0}^{\infty}$ & 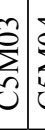 & $\sum_{3}^{5}$ & 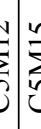 & $\sum_{0}^{2}$ & 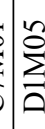 & 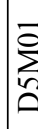 & $\sum_{\substack{0 \\
0}}^{+}$ & 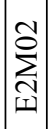 & $\sum_{\exists}^{\circ}$ & $\mid$ & & $\underline{6}$ & & 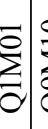 & & the & & $\sum_{3}^{0}$ \\
\hline & i & & 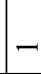 & N & m & $\checkmark$ & {$[n]$} & 10 & $\pi$ & 1 & 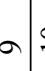 & -7 & $\exists=$ & 7 & 4 & -1 & 1 & $1-$ & - & - & & & & & $\sim$ & & si & & ते \\
\hline
\end{tabular}




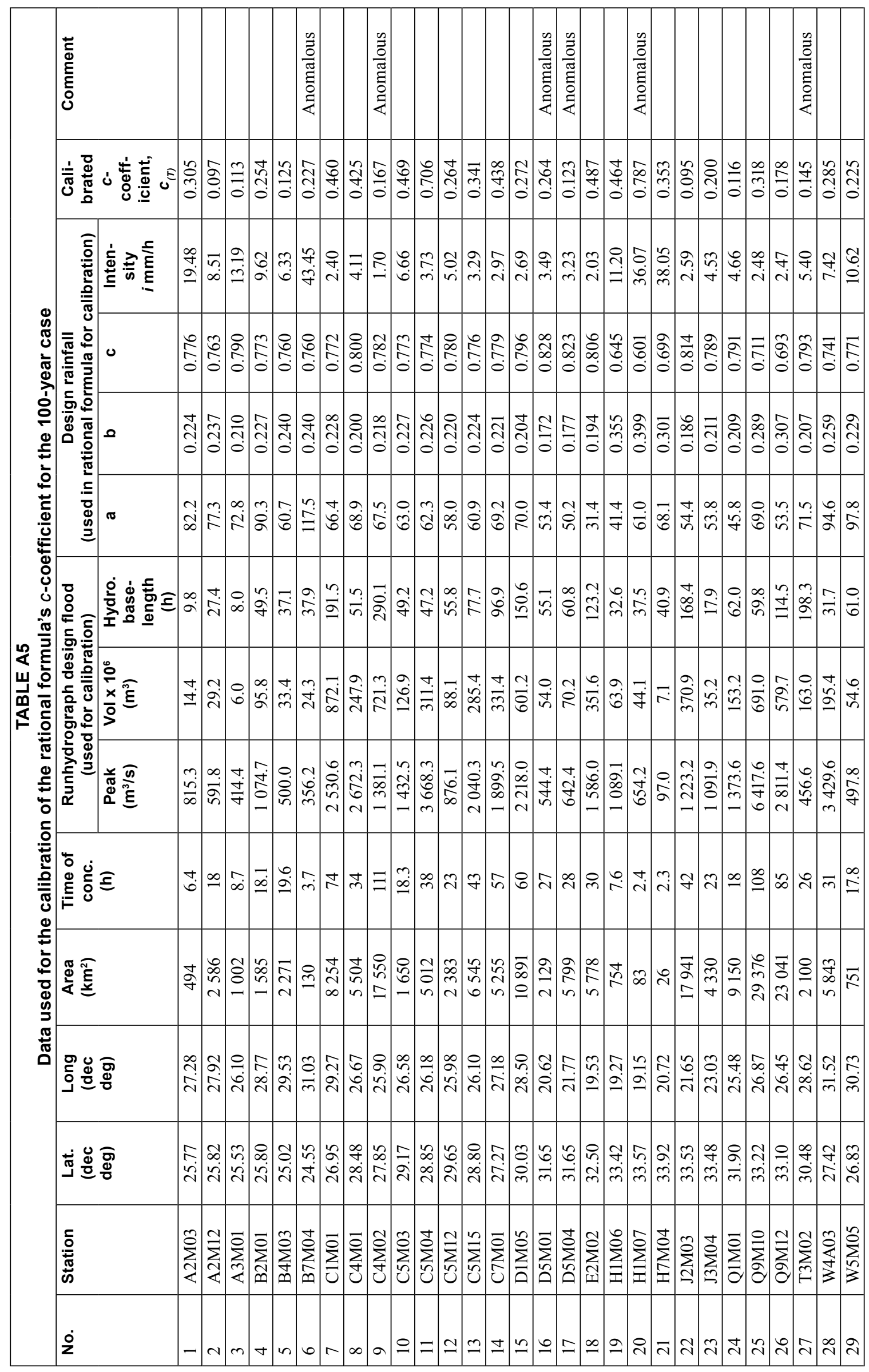




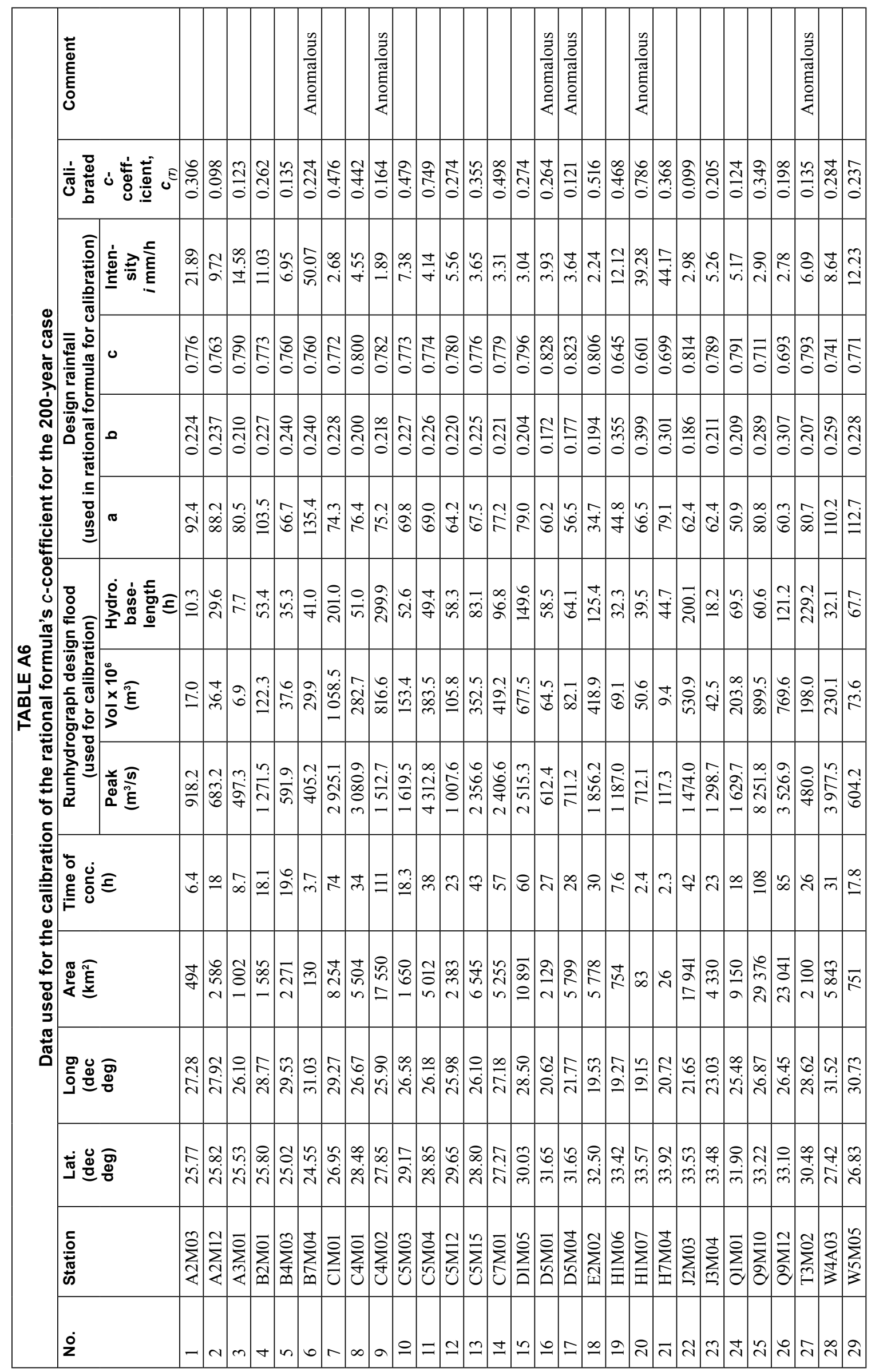




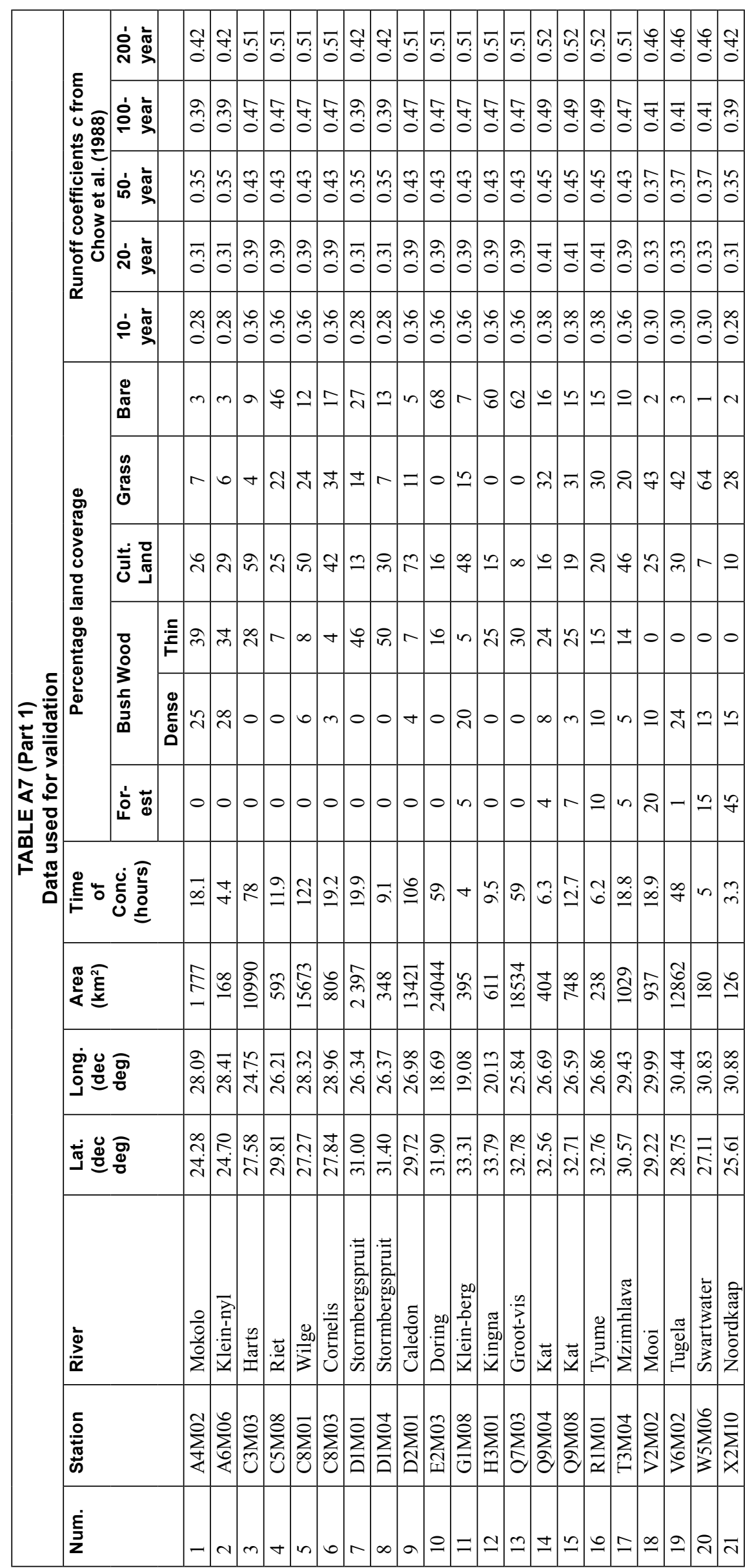



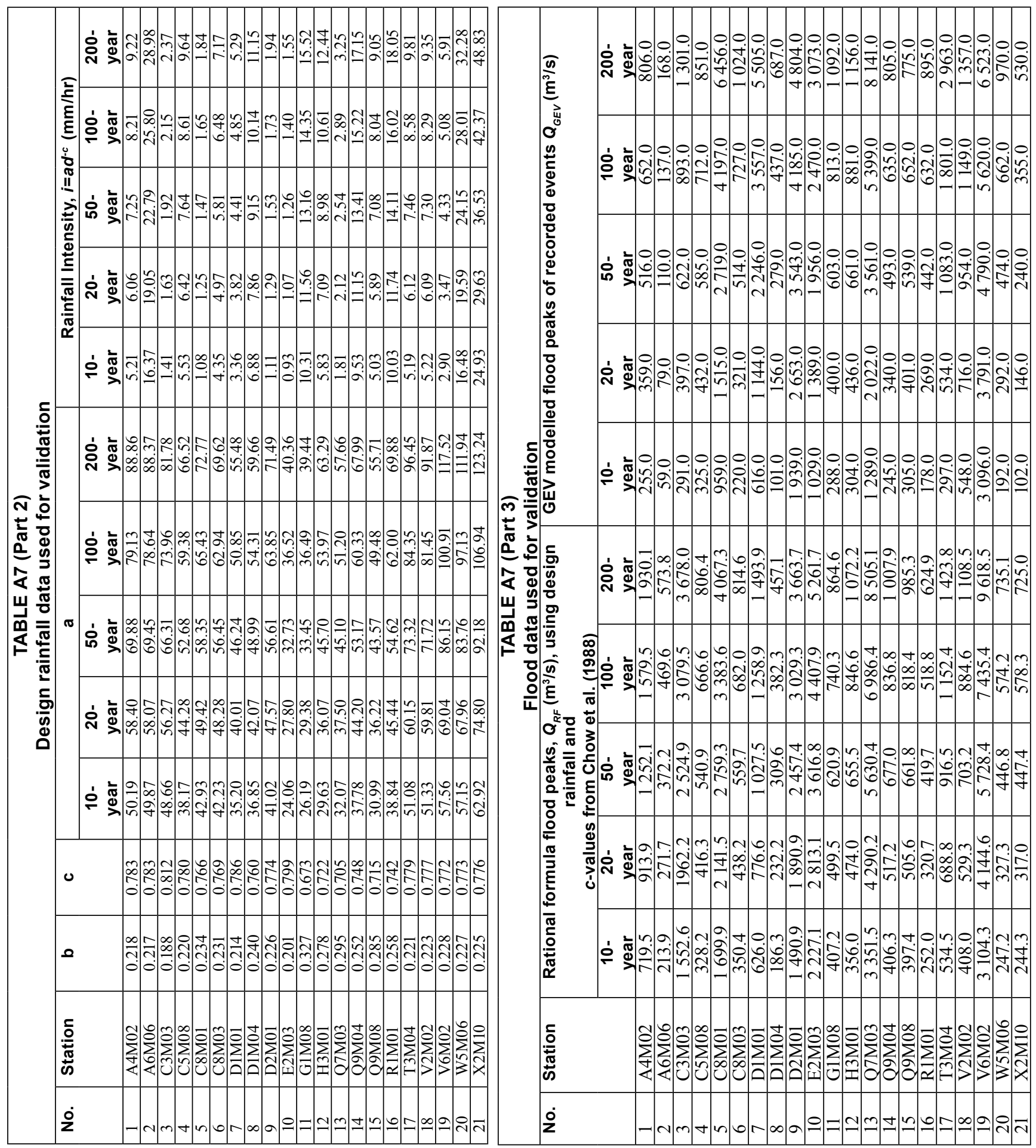